\title{
Five-year records of mercury wet deposition flux at GMOS sites in the Northern and Southern hemispheres
}

\author{
Francesca Sprovieri $^{1}$, Nicola Pirrone ${ }^{2}$, Mariantonia Bencardino ${ }^{1}$, Francesco D'Amore $^{1}$, Helene Angot ${ }^{3}$, \\ Carlo Barbante $^{9,16}$, Ernst-Günther Brunke ${ }^{4}$, Flor Arcega-Cabrera ${ }^{14}$, Warren Cairns ${ }^{16}$, Sara Comero ${ }^{7}$, \\ María del Carmen Diéguez $^{6}$, Aurélien Dommergue ${ }^{3}$, Ralf Ebinghaus ${ }^{5}$, Xin Bin Feng ${ }^{11}$, Xuewu Fu ${ }^{11}$, \\ Patricia Elizabeth Garcia $^{6}$, Bernd Manfred Gawlik ${ }^{7}$, Ulla Hageström ${ }^{8}$, Katarina Hansson ${ }^{8}$, Milena Horvat ${ }^{10}$, \\ Jože Kotnik $^{10}$, Casper Labuschagne ${ }^{4}$, Olivier Magand ${ }^{3}$, Lynwill Martin ${ }^{4}$, Nikolay Mashyanov ${ }^{12}$, Thumeka Mkololo ${ }^{4}$, \\ John Munthe ${ }^{8}$, Vladimir Obolkin ${ }^{15}$, Martha Ramirez Islas ${ }^{13}$, Fabrizio Sena ${ }^{7}$, Vernon Somerset ${ }^{17}$, Pia Spandow ${ }^{8}$, \\ Massimiliano Vardè ${ }^{1,16}$, Chavon Walters ${ }^{17}$, Ingvar Wängberg ${ }^{8}$, Andreas Weigelt ${ }^{5}$, Xu Yang ${ }^{11}$, and Hui Zhang ${ }^{11}$ \\ ${ }^{1}$ CNR Institute of Atmospheric Pollution Research, Rende, Italy \\ ${ }^{2}$ CNR Institute of Atmospheric Pollution Research, Rome, Italy \\ ${ }^{3}$ University Grenoble Alpes, CNRS, IRD, IGE, Grenoble, France \\ ${ }^{4}$ Cape Point GAW Station, Climate and Environment Research \& Monitoring, South African Weather Service, \\ Stellenbosch, South Africa \\ ${ }^{5}$ Helmholtz-Zentrum, Geesthacht, Germany \\ ${ }^{6}$ INIBIOMA-CONICET-UNComa, Bariloche, Argentina \\ ${ }^{7}$ Joint Research Centre, Ispra, Italy \\ ${ }^{8}$ IVL, Swedish Environmental Research Inst. Ltd., Göteborg, Sweden \\ ${ }^{9}$ University Ca' Foscari of Venice, Venice, Italy \\ ${ }^{10}$ Jožef Stefan Institute, Ljubljana, Slovenia \\ ${ }^{11}$ Institute of Geochemistry, State Key Laboratory of Environmental Geochemistry, Chinese Academy of Sciences, \\ Guiyang, China \\ ${ }^{12}$ St. Petersburg State University, St. Petersburg, Russia \\ ${ }^{13}$ Instituto Nacional de Ecología y Cambio Climático (INECC), Mexico City, Mexico \\ ${ }^{14}$ Universidad Nacional Autónoma de México (UNAM), Unidad de Química, Sisal, Mexico \\ ${ }^{15}$ Limnological Institute SB RAS, Irkutsk, Russia \\ ${ }^{16} \mathrm{CNR}$ Institute for the Dynamics of Environmental Processes, Venice, Italy \\ ${ }^{17}$ Natural Resources and the Environment (NRE), Council for Scientific and Industrial Research (CSIR), \\ 7600 Stellenbosch, South Africa
}

Correspondence to: Francesca Sprovieri (f.sprovieri@iia.cnr.it)

Received: 15 June 2016 - Discussion started: 20 July 2016

Revised: 1 February 2017 - Accepted: 3 February 2017 - Published: 22 February 2017

\begin{abstract}
The atmospheric deposition of mercury ( $\mathrm{Hg})$ occurs via several mechanisms, including dry and wet scavenging by precipitation events. In an effort to understand the atmospheric cycling and seasonal depositional characteristics of $\mathrm{Hg}$, wet deposition samples were collected for approximately 5 years at 17 selected GMOS monitoring sites located in the Northern and Southern hemispheres in the framework of the Global Mercury Observation System (GMOS)
\end{abstract}

project. Total mercury (THg) exhibited annual and seasonal patterns in $\mathrm{Hg}$ wet deposition samples. Interannual differences in total wet deposition are mostly linked with precipitation volume, with the greatest deposition flux occurring in the wettest years. This data set provides a new insight into baseline concentrations of $\mathrm{THg}$ concentrations in precipitation worldwide, particularly in regions such as the Southern Hemisphere and tropical areas where wet deposition as 
well as atmospheric $\mathrm{Hg}$ species were not investigated before, opening the way for future and additional simultaneous measurements across the GMOS network as well as new findings in future modeling studies.

\section{Introduction}

Mercury $(\mathrm{Hg})$ is a persistent pollutant of global concern due to its toxicity and its capacity to bioaccumulate in aquatic food chains with serious consequences on human and wildlife health (Driscoll et al., 2013). Long-range atmospheric transport is the main pathway for contamination of remote ecosystems; therefore, atmospheric deposition is the primary indicator for the understanding of its impact on aquatic and terrestrial ecosystems (Schroeder and Munthe, 1998; Lindberg et al., 2002). Hg exists in the atmosphere mainly in three operationally defined forms: gaseous elemental mercury (GEM), oxidized gaseous mercury (GOM), and particulate bound mercury (PBM). Globally, GEM is the predominant form, whereas GOM and PBM are thought to be rapidly dry deposited and wet scavenged by precipitation (Lindberg et al., 2007). Currently, $\mathrm{Hg}$ dry deposition is often estimated by models, using measured ambient concentrations of $\mathrm{Hg}$ and meteorological parameters, due to the lack of existing direct and accurate measurement methodologies (Sexauer Gustin et al., 2012; Zhang et al., 2012). Therefore, the investigation of $\mathrm{Hg}$ fluxes to terrestrial and aquatic surfaces in different parts of the world are often based on wet deposition measurements (Gratz et al., 2009; Fu et al., 2009). Hg wet deposition represents the air-to-surface flux in precipitation (Lindberg et al., 2007). Previous studies suggested that the magnitude of $\mathrm{Hg}$ wet deposition varies geographically and seasonally due to climatic conditions, atmospheric chemistry, and human influences, i.e., emissions of $\mathrm{Hg}$ from anthropogenic sources (Vanarsdale et al., 2005; Selin and Jacob, 2008; Prestbo and Gay, 2009). Current annual atmospheric deposition of $\mathrm{Hg}$ has been estimated to be $3200 \mathrm{Mg} \mathrm{yr}^{-1}$ deposited on land and $3700 \mathrm{Mg} \mathrm{yr}^{-1}$ into oceans (Mason et al., 2012). The preindustrial deposition rate has been estimated to be $1000 \mathrm{Mg} \mathrm{yr}^{-1}$ deposited on land and $2500 \mathrm{Mg} \mathrm{yr}^{-1}$ into oceans (Selin, 2009). Developed countries in North America and Europe have reduced their anthropogenic $\mathrm{Hg}$ use and emissions (Hylander, 2001), but $\mathrm{Hg}$ use and emissions are still occurring widely around the world (Pacyna et al., 2010; Pirrone et al., 2010). In North America, seasonal patterns in THg concentrations in precipitation and $\mathrm{Hg}$ wet deposition amounts have been observed with the highest values in the summer and lowest values in the winter (Mason et al., 2000; Keeler et al., 2005; Choi et al., 2008; Prestbo and Gay, 2009; Pacyna et al., 2010). Explanations for this observation include more effective $\mathrm{Hg}$ scavenging by rain compared to snow (Keeler et al., 2005; Selin and Jacob, 2008), and a greater availability of soluble $\mathrm{Hg}$ due to convective transport in summer events (Keeler et al., 2005; Strode et al., 2007, 2008). Geographic differences in $\mathrm{Hg}$ wet deposition may be explained in part by the proximity to atmospheric sources. Results from the National Atmospheric Deposition Program's (NADP) Mercury Deposition Network (MDN) sites in the northeastern United States exhibit a geographic trend, with southern and coastal sites receiving higher $\mathrm{Hg}$ concentrations in precipitation and wet deposition fluxes (Vanarsdale et al., 2005; Prestbo and Gay, 2009) due to their location closer to the east coast megalopolis and downwind of anthropogenic emission sources such as coal burning power plants and waste incinerators. In addition, gaseous evasion of $\mathrm{Hg}$ from marine waters is a significant global source of GEM which, throughout active oxidation processes, may also contribute to elevated depositional fluxes in coastal regions (Mason and Sheu, 2002). A similar pattern exists in northern Europe with a clear gradient in atmospheric concentrations and deposition (Munthe et al., 2003, 2007; Sprovieri et al., 2016). Hg wet deposition data are therefore important for verifying atmospheric models, understanding the biogeochemical cycling of $\mathrm{Hg}$ on a regional/global scale, and investigating ecosystem impacts. Regional monitoring networks with properly chosen monitoring sites can provide accurate estimates of wet deposition at regional scales. Long-term $\mathrm{Hg}$ wet deposition measurements exist at many locations within already established regional network, such us in the United States as part of the MDN or in Europe as part of the European Monitoring and Evaluation Programme (EMEP); however, before the establishment of the Hg network by the Global Mercury Observation System (GMOS) on a global scale, long-term measurements of ambient $\mathrm{Hg}$ concentrations and measurements of $\mathrm{Hg}$ wet deposition fluxes were lacking (Lindberg et al., 2007; Selin, 2009; Zhang and Wright, 2009) in several regions of the world. Although a number of monitoring stations have been in fact established to better understand the impact of $\mathrm{Hg}$ wet deposition on ecosystems in many countries in the Northern Hemisphere (Wängberg et al., 2007; Prestbo and Gay, 2009; Sanei et al., 2010), the tropical zone and the Southern Hemisphere were particularly lacking in wet deposition data available, in terms of concentrations and deposition $\mathrm{Hg}$ fluxes.

To address this concern, seasonal and annual variations of $\mathrm{Hg}$ wet deposition and concentration at 17 ground-based sites in the Northern and Southern hemispheres were monitored as a part of GMOS (http://www.gmos.eu). Here, an overview of the seasonal/annual $\mathrm{Hg}$ wet deposition patterns across the 17 sites is presented, briefly examining meteorological/climatological conditions, as well as indicators of anthropogenic air mass sources and/or atmospheric chemical conditions in relation to $\mathrm{Hg}$ wet deposition results observed. This study is the first multiyear comparison of $\mathrm{Hg}$ wet deposition worldwide and provides insights into annual and seasonal variations, as well as a spatial gradient in $\mathrm{Hg}$ deposition patterns. 
Table 1. Station locations that are part of the GMOS network and general characteristics of the sites (i.e., code, name, country, latitude, longitude, elevation), including the years of sampling as well as the type of monitoring stations with respect to the Hg measurements carried out as speciated $(\mathrm{M})$ or not $(\mathrm{S})$. M/S or $\mathrm{S} / \mathrm{M}$ indicates change of the site from master to secondary or vice versa. External GMOS partners are indicated in bold.

\begin{tabular}{|c|c|c|c|c|c|c|c|c|c|}
\hline & Code & Name & Country & Lat & Long & $\begin{array}{r}\text { Elev. } \\
\text { (m a.s.1.) }\end{array}$ & $\begin{array}{l}\text { Collector } \\
\text { type }\end{array}$ & $\begin{array}{r}\text { Years of } \\
\text { sampling }\end{array}$ & Type* \\
\hline \multicolumn{10}{|c|}{ Northern Hemisphere } \\
\hline 1 & NYA & Ny-Ålesund & Norway & 78,90 & 11,88 & 12 & IVL bulk & 2012-2015 & $\mathbf{M}$ \\
\hline 2 & PAL & Pallas & Finland & 68,00 & 24,24 & 340 & IVL bulk & 2011-2014 & $\mathrm{S}$ \\
\hline 3 & RAO & Råö & Sweden & 57,39 & 11,91 & 5 & IVL bulk & 2011-2014 & M \\
\hline 4 & MHE & Mace Head & Ireland & 53,33 & $-9,91$ & 5 & wet only & 2012-2014 & $\mathrm{S}$ \\
\hline 5 & LIS & Listvyanka & Russia & 51,85 & 104,89 & 670 & wet only & 2012-2013 & $\mathrm{S}$ \\
\hline 6 & CMA & Col Margherita & Italy & 46,37 & 11,79 & 2545 & IVL bulk & 2014 & $\mathrm{~S}$ \\
\hline 7 & ISK & Iskrba & Slovenia & 45,56 & 14,86 & 520 & wet only & 2011-2015 & M \\
\hline 8 & $\mathrm{MCH}$ & Mt. Changbai & China & 42,40 & 128,11 & 741 & wet only & 2011-2014 & $\mathrm{M} / \mathrm{S}$ \\
\hline 9 & LON & Longobucco & Italy & 39,39 & 16,61 & 1379 & wet only & 2012-2013 & M \\
\hline 10 & MWA & Mt. Waliguan & China & 36,29 & 100,90 & 3816 & wet only & 2012-2014 & M \\
\hline 11 & MAL & Mt. Ailao & China & 24,54 & 101,03 & 2503 & wet only & 2011-2014 & $\mathrm{S} / \mathrm{M}$ \\
\hline \multicolumn{10}{|c|}{ Tropics } \\
\hline 12 & SIS & Sisal & Mexico & 21,16 & $-90,05$ & 7 & wet only & 2013-2014 & $\mathrm{S}$ \\
\hline 13 & CST & Celestún & Mexico & 20,86 & $-90,38$ & 3 & wet only & 2012-2013 & $\mathrm{S}$ \\
\hline \multicolumn{10}{|c|}{ Southern Hemisphere } \\
\hline 14 & AMS & Amsterdam Island & TAAF & $-37,80$ & 77,55 & 70 & wet only & 2013-2014 & $M$ \\
\hline 15 & $\mathrm{CPT}$ & Cape Point & South Africa & $-34,35$ & 18,49 & 230 & wet only & 2011-2015 & $\mathrm{S}$ \\
\hline 16 & CGR & Cape Grim & Australia & $-40,68$ & 144,69 & 94 & IVL bulk & 2013-2015 & $\mathrm{S}$ \\
\hline 17 & BAR & Bariloche & Argentina & $-41,13$ & $-71,42$ & 801 & wet only & 2014-2015 & M \\
\hline
\end{tabular}

${ }^{*} \mathrm{M}=$ master; $\mathrm{S}=$ secondary. TAAF indicates Terres Australes et Antarctiques Françaises.

\section{Experimental}

\subsection{GMOS ground-based monitoring sites}

The global Hg monitoring network has been established in the framework of the GMOS and presented in Sprovieri et al. (2016). It has been developed by integrating previously ongoing ground-based $\mathrm{Hg}$ monitoring stations as part of regional networks with those established as part of GMOS also in regions of the world where atmospheric $\mathrm{Hg}$ measurements were previously limited. To date, the GMOS network consists of 43 monitoring stations worldwide distributed and located in climatically diverse regions, including polar areas (Sprovieri et al., 2016). In the present study, we refer the discussion on $\mathrm{Hg}$ wet deposition to a representative number of 17 ground-based sites distributed in the Northern and Southern hemispheres (Fig. S1 in the Supplement). Table 1 provides key information on the 17 monitoring sites such as their location (country, coordinates, etc.), elevation (m a.s.l.), and type of monitoring stations (master and secondary sites) with respect to the atmospheric $\mathrm{Hg}$ measurements performed (Hg speciation and total gaseous mercury - TGM/GEM mea- surements, respectively) along with $\mathrm{THg}$ wet deposition sampling.

\subsection{Sample collection, analytical procedure, and QA/QC}

Precipitation samples were collected across the sites primarily using wet-only collectors, (i.e., N-CON MDN or the Eigenbrodt NSA 171 wet-only samplers). Where necessary, due to site constraints or operator availability, few GMOS sites (Table 1) alternatively collected bulk precipitation samples using the Swedish Environmental Research Institute (IVL) bulk sampler (Chazin et al., 1995; Munthe et al., 2011; UNI, 2010). The detailed description of the Swedish bulk sampler is reported elsewhere (Chazin et al., 1995; UNI, 2010), where it also has been highlighted that utilizing clean handling and analysis technique is equivalent to using a wet-only sampler in remote areas, and/or areas not subject to large amounts of anthropogenic emission sources, as is the case in most of the GMOS groundbased sites. Within GMOS, special attention was paid with respect to protocol harmonization, data quality collection, and data management in order to assure a full comparability of site-specific observational data sets. During the imple- 
mentation stage of the GMOS global network, harmonized standard operating procedures (SOPs) as well as common quality assurance/quality control $(\mathrm{QA} / \mathrm{QC})$ protocols have been addressed (Munthe et al., 2011) in accordance with the measurement practice adopted in well-established regional monitoring networks and based on the most recent literature (Brown et al., 2010a, b; Steffen et al., 2012; Gay et al., 2013). For THg in precipitation, an ad hoc standard operating procedure has been developed and adopted within the network. Furthermore, the management of the measurement program at most of the GMOS sites consisting of analysis of all precipitation samples, cleaning procedures, and distribution of the sample bottles to all sites, has been performed by three reference laboratories (IVL, Sweden; CNR-IIA (CNR Institute of Atmospheric Pollution Research), Italy; and IJS (Jožef Stefan Institute), Slovenia), whereas the precipitation samples related to some other GMOS sites, such as in Russia - Listvyanka (LIS); in China - Mt. Waliguan (MWA), Mt. Ailao (MAL), and Mt. Changbai (MCH); and in South Africa - Cape Point (CPT), have been analyzed by local laboratories. The analytical performance and the QA/QC of the analysis carried out by the reference laboratories as well as by the local laboratories were confirmed by the results achieved during international intercomparison exercises for $\mathrm{Hg}$ in water (i.e., Brooks Rand Instruments Interlaboratory Comparison Study). GMOS sites predominantly collected biweekly samples. However, considering the spatial distribution and the diversity of meteorological parameters and conditions characterizing the monitoring site locations, the sampling frequency was sometimes different across the sites. THg concentrations in precipitation samples, refrigerated and kept in the dark before the analysis (to avoid photo-induced reduction of the $\mathrm{Hg}$ in the precipitation sample), were determined according to the US EPA Method 1631 (version E) (1631 U. E. M., 2002): each sample was first oxidized by $\mathrm{BrCl}(0.5 \mathrm{~mL} / 100 \mathrm{~mL}$ sample), followed by neutralization with hydroxylamine hydrochloride $\left(\mathrm{NH}_{2} \mathrm{OH} \cdot \mathrm{HCl}\right)$. Stannous chloride $\left(\mathrm{SnCl}_{2}\right)$ was then added to the sample to reduce $\mathrm{Hg}_{(\mathrm{aq})}^{2+}$ to $\mathrm{Hg}_{(\mathrm{g})}^{0}$ which was quantified by cold vapor atomic fluorescence spectrometry (CVAFS) using a Tekran Mercury Analysis System Model 2600 (Tekran Inc. Corporation, Canada). Working $\mathrm{Hg}$ standards solutions were obtained from a standard reference material (SRM) produced by accredited laboratory (ISO/IEC 17025). Calibration standards were analyzed in the range from 0.2 to $100 \mathrm{ng} \mathrm{L}^{-1}$ (recovery 93-109\%). The standard curve was used within the coefficient of determination $\left(r^{2}\right)$ greater than 0.998 (linear). Initial (IPR) and ongoing precision and recovery (OPR) solutions (5 ppt) were analyzed prior to the analysis of samples and again after every 12 samples (recovery 91$103 \%)$. These values were within the quality control acceptance criteria for performance in the EPA Method 1631e. The method detection limit (MDL; 40 CFR (Code of Federal Regulations) 136, Appendix B) for $\mathrm{Hg}$ has been determined to be $0.02 \mathrm{ng} \mathrm{L}^{-1}$. The minimum level of quantifi- cation (ML) has been established as $0.05 \mathrm{ng} \mathrm{L}^{-1}$ for $\mathrm{THg}$. The QA/QC of the analysis were obtained using replicates, method blanks, field blanks, initial/ongoing precision recovery (IPR/OPR) standards, matrix spikes, and certified reference materials (CRMs) with different certified Hg concentrations. Method and field blanks were always below the respective MDL, indicating minimal contamination during sampling, transport, and treatment for this study. Additionally, the sampling train materials (fluorinated polyethylene - FLPE - bottles, cylindrical glass funnels, Teflon adapters along with the glass capillary S-shaped tubes to prevent loss of mercury from the sample, etc.) were thoroughly acidcleaned and rinsed with ultra-pure water in the $\mathrm{Hg}$ laboratory before and after sampling steps, and randomly tested for $\mathrm{Hg}$ concentrations; they were always below the MDL. All of these materials have been triple-bagged in zip-type plastic bags to keep them clean prior to use in the field. The results of "blanks" analysis allowed us to exclude possible contamination of all samples during different steps.

\subsection{Hg wet deposition flux calculation}

Considering the geographical distribution of the 17 sites located at different latitude and longitude, and therefore, under different meteorological and climatological conditions, the precipitation was not collected over an entire year at each station due to limited amount of precipitation samples occurring during specific periods (i.e., dry seasons). Therefore, $\mathrm{Hg}$ flux was necessarily estimated based on the volume-weighted mean (VWM) concentration and the precipitation amount collected at each site during the times that the $\mathrm{Hg}$ sampler was operating. This means that the $\mathrm{THg}$ wet deposition flux has been approximately calculated by the following equation:

$F_{\mathrm{W}}=C_{\mathrm{H}_{\mathrm{g} x}} \sum_{i=1}^{i=n} P^{i} 1 / 1000$,

where $F_{\mathrm{W}}$ is the THg wet deposition flux $\left(\mu \mathrm{g} \mathrm{m}^{-2} \mathrm{yr}^{-1}\right)$ and $C_{\mathrm{H}_{\mathrm{g} x}}$ is the VWM concentration of $\mathrm{THg}\left(\mathrm{ng} \mathrm{L}^{-1}\right) . P^{i}(\mathrm{~mm}$; $1 \mathrm{~mm}=1 \mathrm{~L} \mathrm{~m}^{-2}$ ) represents the precipitation amount associated with each wet deposition sample.

It is also necessary point out that the "precipitation" and "rainfall" terms throughout this work have been interchangeably used and, further, rainfall included all forms of precipitation (i.e., rain, frozen). The frozen precipitation has been considered as "liquid rain equivalent". In addition, to overcome the irregularity in time-sampling frequency of the rainy samples collected at each site (see Tables S3 and S4) the rainfall amounts as well as $\mathrm{THg}$ wet deposition flux weighted data have been normalized with respect to the ideal timesampling period, equal to 15 days, as previously established in our GMOS standard operating procedures (Munthe et al., 2011). In this way, all data resulted comparable and harmonized. 


\section{Hg wet deposition patterns and interannual variability}

The annual variations in $\mathrm{THg}$ concentration and wet deposition recorded at all 17 monitoring GMOS sites are summarized in Tables S1 and S2. Both tables list the monitoring sites according to their latitude and rain amounts collected, the number of the sampling days, as well as the annual wet deposition flux calculated for each site for each year in the period 2011-2015. The rainfall amounts as well as THg wet deposition flux weighted data have been normalized with a 15-day sampling reference as described in the section above. Annual THg wet deposition fluxes calculated at each site according to their latitude are shown in Fig. 1. The Hg deposition at each site tends to vary from year to year, but to a different degree at different locations. It is well known that the magnitude of $\mathrm{Hg}$ wet deposition varies geographically and seasonally due to different meteorological and climatic conditions, atmospheric chemistry, and anthropogenic influences (Vanarsdale et al., 2005; Selin and Jacob, 2008; Prestbo and Gay, 2009). Therefore, considering the 11 sites distributed in the Northern Hemisphere, the discussion of the results will be separately related to the 7 European sites (ruling out the discussion on the data related to LIS site, due to the lower number of samples collected over the sampling period and thus not representative enough for such a conclusion) and the 3 Chinese sites (see Tables S1-S4) as well as those located in the tropical area and the sites distributed in the Southern Hemisphere. Considering the THg wet deposition from 2012 to 2014 at the European sites, there appears to be a geographical trend with an increase in $\mathrm{Hg}$ deposition from north (Arctic area, i.e., Ny-Ålesund - NYA, Norway; Pallas - PAL, Finland) to south in the Northern Hemisphere (i.e., Råö RAO, Sweden; Mace Head - MHE, Ireland; Listvyanka LIS, Russia; Col Margherita - CMA, Italy; Longobucco LON, Italy). At the Chinese sites, as well as at lower latitude (i.e., tropical area and Southern Hemisphere), no northsouth spatial trend has been observed. However, it is important to point out that the sites in the Southern Hemisphere are limited in number compared to those in the Northern Hemisphere and the data coverage is less complete for each year considered. This makes detailed evaluation of spatial trends at the southern sites difficult. In addition, apart from CPT, no historical records of $\mathrm{THg}$ deposition exist for the new stations established in the GMOS project.

The geographical trend observed at the European stations with higher deposition of $\mathrm{Hg}$ in southern sites than in the north is in line with emission patterns with the main source areas in central and eastern Europe. The present data in combination with ground-based atmospheric $\mathrm{Hg}$ measurements performed within the GMOS project during 20122015 period indicate that these findings are in good agreement with the geographical distribution of atmospheric $\mathrm{Hg}$ with a downward gradient from the Northern to the Southern Hemisphere (Sprovieri et al., 2016). Figures 1 and 2

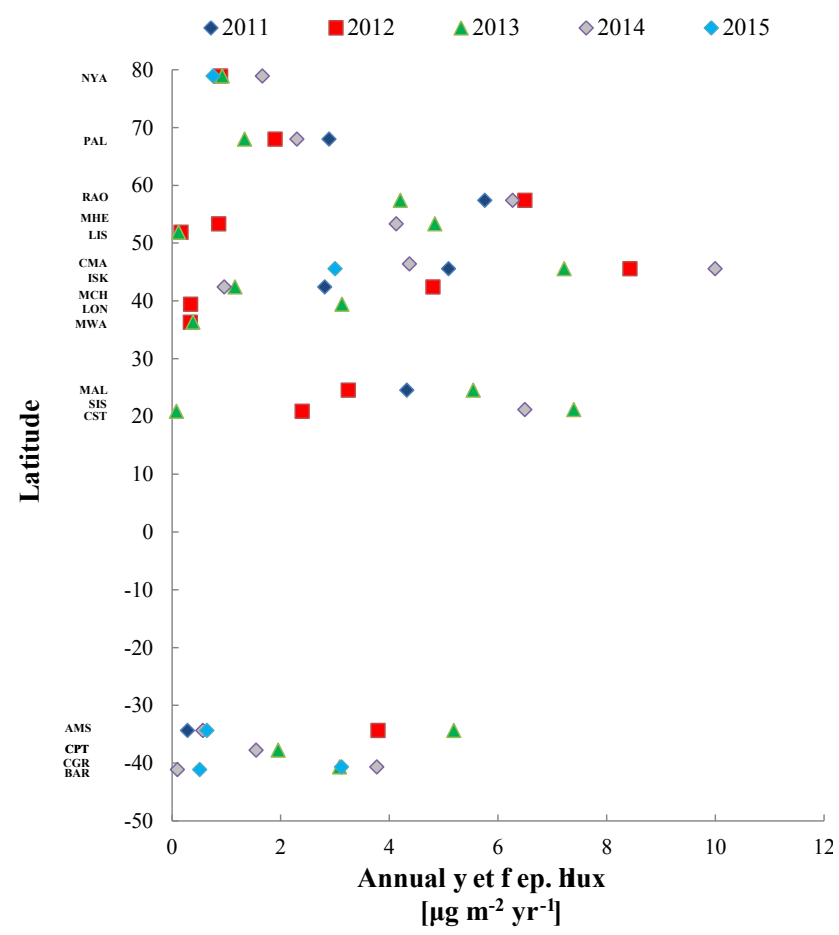

Figure 1. Scatterplot reporting the annual wet deposition fluxes versus latitude observed at the 17 GMOS sites during 2011-2015.

show, from 2012 to 2014 (the period with more data coverage), a general increasing of $\mathrm{THg}$ wet deposition from the NYA station to Iskrba (ISK), Slovenia; this finding is particularly evident during the 2013 and 2014 (Fig. 2) event if the pattern is not apparent for the LON site in 2013 and for MHE and CMA for 2014, indicating the influence of other parameters and/or atmospheric transport pathways. In Fig. 2, the $\mathrm{THg}$ wet deposition fluxes calculated on an annual basis are reported, taking into account the annual precipitation amounts recorded at each site. It well known that wet deposition of atmospheric $\mathrm{Hg}$ at any given location is influenced by factors such as (a) atmospheric $\mathrm{Hg}$ concentration depending upon the local, regional, and global sources; (b) site location in relation to the predominant wind direction in relation to the source areas; (c) precipitation amount which removes $\mathrm{Hg}$ from the atmosphere; (d) type of precipitation (rain or snow); (e) length of precipitation events which affect $\mathrm{Hg}$ concentrations; (f) height and thickness of the precipitating cloud layer in the atmosphere and the degree of convection involved; and ( $\mathrm{g}$ ) at least (but not less important than the others) the oxidizing capacity of the atmosphere, which can be the dominant factor particularly in remote/polar areas. $\mathrm{Hg}$ concentrations appear to be higher at the beginning of a precipitation event (i.e., rain or snow), and lower at the end of a precipitation event (Keeler et al., 2005; Gratz et al., 2009; Prestbo and Gay, 2009; Chen et al., 2014). This is most evident during periods of prolonged precipitation (i.e., over a period of several days). It is obvious therefore that the $\mathrm{Hg}$ 


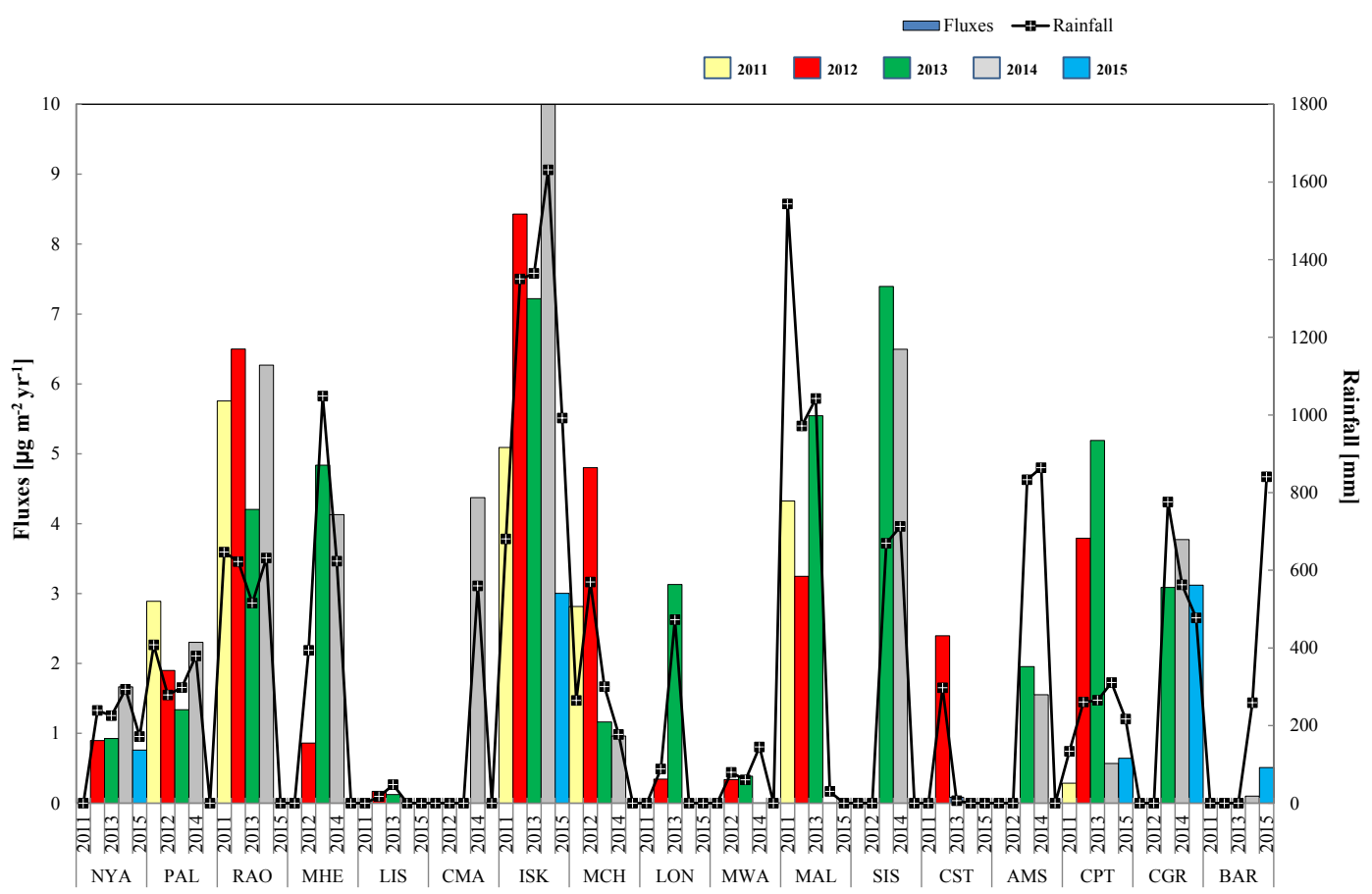

Figure 2. Annual wet deposition fluxes and the corresponding cumulative precipitation amounts (rainfall), observed at the 17 GMOS sites during 2011-2015.

deposition obtained at some sites should be strongly influenced by the precipitation amounts. In particular, the annual deposition amounts during the 2011-2015 period show the influence of the precipitation amount on $\mathrm{Hg}$ deposition between, for example, the RAO site and the PAL site (Fig. 2). The THg wet deposition fluxes recorded during 2011-2014 were, respectively, 5.8, 6.5, 4.2, and $6.3 \mu \mathrm{g} \mathrm{m}^{-2} \mathrm{yr}^{-1}$ at the RAO site. This is more than 2 times higher than at Pallas during the same years $\left(2.9,1.9,1.3\right.$, and $\left.2.3 \mu \mathrm{g} \mathrm{m}^{-2} \mathrm{yr}^{-1}\right)$, and since the precipitation amounts are also a factor of 2 higher at the RAO site in comparison to PAL, the $\mathrm{Hg}$ deposition results seem to be consistent with this increase in the south compared to the northern sites. These findings also confirmed the results obtained by Munthe et al. (2007) during an assessment on available $\mathrm{Hg}$ data in precipitation carried out from 1996 to 2002 at five Scandinavian EMEP monitoring stations, and among them also at the RAO and PAL GMOS sites. Munthe et al. (2007) highlights, in fact, that the highest annual $\mathrm{Hg}$ wet deposition and yearly averaged $\mathrm{THg}$ concentrations in precipitation have been recorded at the southern Scandinavian coastal sites where the highest average annual deposition amounts also occurred. The annually based THg wet deposition flux $\left(\mu \mathrm{g} \mathrm{m}^{-2} \mathrm{yr}^{-1}\right)$ calculated, conversely, at MCH, MWA, and MAL shows no significant geographical trend with high variability and notable differences in concentrations among the sites during the same period. These stations are all remote sites in China, and considering the 2012-2014 period, which is the most representative in terms of number of samples recorded, it is possible to see that the averaged THg wet deposition fluxes $\left(\mathrm{ng} \mathrm{m}^{-2} \mathrm{day}^{-1}\right)$ in remote areas of China were not significantly higher than the values observed at the rest of the GMOS sites (i.e., ISK, MHE, RAO) (Fig. 2).

At the sites located at lower latitude and Southern Hemisphere, the relationship between precipitation amount and deposition was not as evident as in the Northern Hemisphere. At the Sisal monitoring station (SIS), a coastal site of the tropical area located on the Yucatán Peninsula (Gulf of Mexico), the 2013 annual wet THg deposition flux was $7.4 \mu \mathrm{g} \mathrm{m}^{-2} \mathrm{yr}^{-1}$, whereas the rainfall amount was $669.6 \mathrm{~mm}$, which is lower than the rainfall recorded at the remote southern sites, such as Amsterdam Island (AMS) $(833.2 \mathrm{~mm}$ rainfall), southern Indian Ocean, and Cape Grim (CGR), Australia (775.6 $\mathrm{mm}$ rainfall), where the annual wet $\mathrm{Hg}$ deposition flux recorded was considerably lower at 1.95 and $3.1 \mu \mathrm{g} \mathrm{m}^{-2} \mathrm{yr}^{-1}$, respectively (see Tables $\mathrm{S} 1$ and S2). The 2013 and 2014 annual wet deposition fluxes recorded at SIS are comparable or higher than those observed at most GMOS sites in the Northern and Southern hemispheres (Tables S1 and S2). Because of the $\mathrm{Hg}$ deposition at any given location is dependent upon both THg concentrations (which have a geographical component) in precipitation and precipitation amounts (Munthe et al., 2007), the results obtained across the sites located from the tropical area to the Southern Hemisphere highlighted that, in this case, the geographical component in terms of local meteorology and local emis- 
sion sources has had a higher influence on the THg results. During the sampling period, SIS was typically influenced by air masses originating from the Atlantic Ocean coming from east-southeast, but crossing the Caribbean islands and/or Central/South America with occasional air masses coming from east-northeast mostly during the winter period and crossing the south of Florida and Caribbean archipelago prior to arriving at the monitoring site (Sena et al., 2015; Sprovieri et al., 2016). Very few $\mathrm{Hg}$ deposition measurements have been performed at tropical latitudes (Hansen and Gay, 2013; Shanley et al., 2008, 2015). Shanley et al. (2015), in a study over 7 years (2005-2012) on Hg wet deposition in Puerto Rico (Caribbean archipelago, US), highlighted that despite receiving prevailing unpolluted air off the Atlantic Ocean from northeasterly trade winds, wet $\mathrm{Hg}$ deposition recorded at the site was about $30 \%$ higher than that observed in Florida and the Gulf Coast, which in turn are the highest deposition areas in the US, and thus was greater than at all other MDN sites. The wet $\mathrm{Hg}$ deposition map from the MDN, in fact, shows a general pattern of relatively low deposition over the western US $\left(\sim 2-5 \mu \mathrm{g} \mathrm{m}^{-2} \mathrm{yr}^{-1}\right)$ and higher in the eastern US (6-15 $\mu \mathrm{g} \mathrm{m}^{-2} \mathrm{yr}^{-1}$ ) due to increasing precipitation and location of important anthropogenic $\mathrm{Hg}$ sources. In addition, in the eastern US, a north-south latitudinal gradient exists in wet $\mathrm{Hg}$ loading, with wet deposition reaching a maximum in the southeastern US over Florida (Prestbo and Gay, 2009; Selin, 2014). Despite its unpolluted tropical setting, Puerto Rico seems to fit as a southern extension to a latitudinal gradient of increasing $\mathrm{Hg}$ deposition from north to south in the eastern US (Shanley et al., 2015). The high wet $\mathrm{Hg}$ deposition at SIS can be directly linked to the meteoclimatic conditions and pressure systems typical of the tropics. The higher THg wet deposition observed at latitudes lower than south of Florida and or Mexico (such as in Puerto Rico $\left(27.9 \mu \mathrm{g} \mathrm{m}^{-2} \mathrm{yr}^{-1}\right)$, an unpolluted tropical site crossed often by air masses detected at SIS prevalently in summer and fall and less so in winter) also suggests that frequent high convective clouds in this subtropical region likely access the reservoir of oxidized $\mathrm{Hg}$ species in the upper free troposphere (Guentzel et al., 2001; Driscoll et al., 2013; Nair et al., 2013). Shanley et al. (2015) found that the high $\mathrm{Hg}$ deposition was not correlated with GOM at ground level but with the maximum height of rain detected within clouds (obtained from the echo tops using the NOA-NEXRAD radar station), suggesting that droplets in high convective cloud tops scavenged GOM from above the mixing layer (Shanley et al., 2015 and references therein). Numerous studies suggest in fact that the upper free troposphere holds a large pool of GOM that has been oxidized from the global Hg pool (Driscoll et al., 2013; Swartzendruber et al., 2006; Weiss-Penzias et al., 2009) and that frequent high convective clouds occurring in tropical regions, particularly closer to the Equator, scavenge GOM by precipitation being readily soluble (Lindberg et al., 2007; Selin and Jacob, 2008; Holmes et al., 2010). Closer to the Equator, the Hadley cell structure indeed gives way to the in- tertropical convergence zone (ICT), and the atmospheric circulation there may affect upper-atmosphere $\mathrm{Hg}$ levels. The few measurements in the Northern Hemisphere tropics, such as at SIS, generally indicate lower $\mathrm{Hg}$ fluxes than those measured at lower tropical latitude probably due to fewer convective rain events with clouds that reach the upper atmosphere (Shanley et al., 2015 and references therein). The higher annual wet $\mathrm{Hg}$ deposition observed at SIS compared to the other GMOS sites could be also due to a contribution of air masses crossing areas with discrete anthropogenic emission sources, particularly in late spring and summer, such as the metropolitan area of San Juan and/or minor industrial plants in Fajardo and the Antilles islands, and/or from air masses crossing, particularly in winter, several coal power plants and waste incinerations in the southern United States and southern Florida (Latysh and Wetherbee, 2007). In addition, also legal and/or illegal gold mining activities, which are widespread (Veiga et al., 2006; Sprovieri et al., 2016) in the southern regions of the Yucatán Peninsula (Nicaragua, Guatemala, etc.), could contribute to the $\mathrm{Hg}$ wet deposition at SIS.

The southern sites, AMS, CPT, CGR, and Bariloche (BAR, Argentina) are more remote compared to SIS. AMS is a very small island located in the southern Indian Ocean where atmospheric $\mathrm{Hg}$ concentrations recorded during the same period were remarkably steady with an annual median of $1.03 \pm 0.10 \mathrm{ng} \mathrm{m}^{-3}$ and lower than those recorded at the tropical sites (Angot et al., 2014; Sprovieri et al., 2016) but slightly higher than annual averages and medians recorded at CGR in 2013 (Slemr et al., 2014). Both AMS and CGR, for most of the time, receive clean marine air masses (Slemr et al., 2014; Angot et al., 2014). Previous studies (Mason and Sheu, 2002; Holmes et al., 2009; Sprovieri et al., 2003, 2010a, b) analyzed atmospheric observations of GOM from Mediterranean, Pacific, and Atlantic cruises in terms of $\mathrm{Hg}$ chemistry and deposition in the marine atmosphere, and suggested that elevated levels of halogen atoms, and in particular of bromine $(\mathrm{Br})$ in the marine boundary layer (MBL) are an important source of GOM from oxidation of GEM that are more readily deposited throughout seasalt aerosols followed by aerosol deposition. GEM evasion from marine waters therefore could represent a significant source of atmospheric $\mathrm{Hg}$ which contributes to depositional fluxes in marine regions (Mason and Sheu, 2002), such as AMS and CGR. In 2013, among the southern sites, the highest annual THg wet deposition fluxes has been recorded at CPT $\left(5.2 \mu \mathrm{g} \mathrm{m}^{-2} \mathrm{yr}^{-1}\right)$ which also showed both the lowest precipitation amount $(264.9 \mathrm{~mm})$ and the number of sampling days (Tables S1 and S2) compared to AMS (with an annual wet deposition flux of $1.95 \mu \mathrm{g} \mathrm{m}^{-2} \mathrm{yr}^{-1}$, considering a rainfall of $833.2 \mathrm{~mm}$ ) and CGR (with wet deposition flux of $3.1 \mu \mathrm{g} \mathrm{m}^{-2} \mathrm{yr}^{-1}$, considering a rainfall of $775.6 \mathrm{~mm}$ ). These findings have not been observed at CPT in 2014 with the lowest annual wet deposition flux $\left(0.57 \mu \mathrm{g} \mathrm{m}^{-2} \mathrm{yr}^{-1}\right)$ and comparable precipitation amounts and number of sampling days 


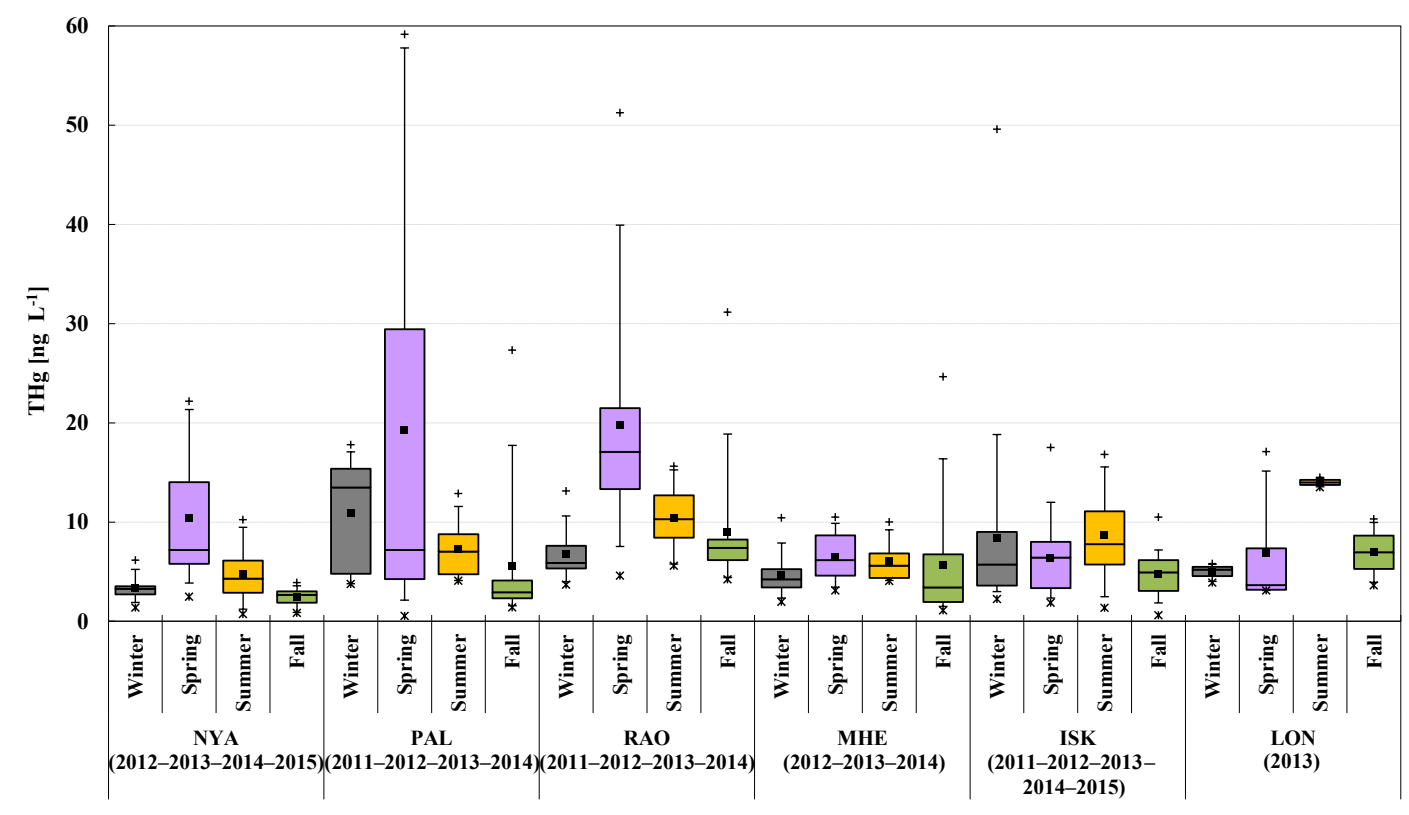

Figure 3. Seasonal distribution of volume-weighted THg concentration in precipitation at the European GMOS sites from 2011 to 2015. Each box includes the median (midline), mean (ם), 25th and 75th percentiles (box edges), 5th and 95th percentiles (whiskers), minimum (*), and maximum $(+)$.

of the year before (see Tables S1 and S2). CPT is situated on the southern tip of South Africa (Sprovieri et al., 2016; Brunke et al., 2016), and during the wetter season (MayOctober) normally precipitation increased due to the passage of cold fronts moving from west to east (Brunke et al., 2016). In a previous study by Brunke et al. (2004), it was highlighted that CPT receives continental and polluted air masses more frequently during the winter period with air masses advected to the station from north to northwestern (Rautenbach and Smith, 2001; Brunke et al., 2004) regions where the Gauteng and Mpumalanga provinces are located. These South African areas represent the major anthropogenic $\mathrm{Hg}$ sources with former mine dumps from gold mining and large coal-burning power stations (Dabrowski et al., 2008). Therefore, in the first instance, the highest annual average THg wet deposition flux observed at CPT in 2013 compared to the other southern sites, which received more precipitation amounts than the CPT site, could be prevalently influenced by regional/largescale emission sources during the sampling period. Measurements of atmospheric Hg deposition in BAR have been carried out for the first time from 2014 to 2015. The BAR site has been established inside a well-protected natural reserve in northern Patagonia, on the shore of the Gutierrez River, southeast of the Nahuel Huapi lake. GEM records at the BAR station resemble background concentrations comparable to levels found in Antarctica and other remote locations of the Southern Hemisphere with annual mean GEM concentrations of $0.9 \pm 0.14 \mathrm{ng} \mathrm{m}^{-3}$ (Diéguez et al., 2015; Sprovieri et al., 2016). The annual THg wet deposition flux calculated at BAR in 2014 was very low $\left(0.1 \mu \mathrm{g} \mathrm{m}^{-2} \mathrm{yr}^{-1}\right)$; however, it is necessary to point out that the number of samples carried out during the year was scarce $(n=91)$ and therefore less representative than that recorded in 2015 and calculated over a number of sampling days of nearly $50 \%$ of the year. The $2015 \mathrm{THg}$ wet deposition flux was $0.5 \mu \mathrm{g} \mathrm{m}^{-2} \mathrm{yr}^{-1}$, which is lower than those recorded at most of the other southern GMOS sites.

\section{Seasonal patterns and influence of meteorological conditions on $\mathrm{Hg}$ wet deposition}

\subsection{European stations}

In this study, seasons are delineated according to the meteorological definition. Since THg wet deposition flux depends on the total precipitation amount and the concentration of total $\mathrm{Hg}$ in that precipitation, the seasonal cycles of both these parameters are shown along with the cycles of $\mathrm{Hg}$ wet deposition in Figs. 3-5.

In particular, Figs. 3 and 4 show that seasonal trends of THg in precipitation are clearly evident at all sites, with increased $\mathrm{Hg}$ concentrations and deposition observed during spring and summer months at most of them, implying a significant dependence on meteorological conditions throughout the years. The seasonal variability in $\mathrm{Hg}$ concentrations and $\mathrm{Hg}$ deposition has been reported in previous studies in North America (Hoyer et al., 1995; Landis and Keeler, 1997) and Europe (Iverfeldt, 1991; Munthe et al., 2007). The warm month maximum in seasonal $\mathrm{THg}$ wet deposition is predominant at most European GMOS sites (Fig. 4) except at 


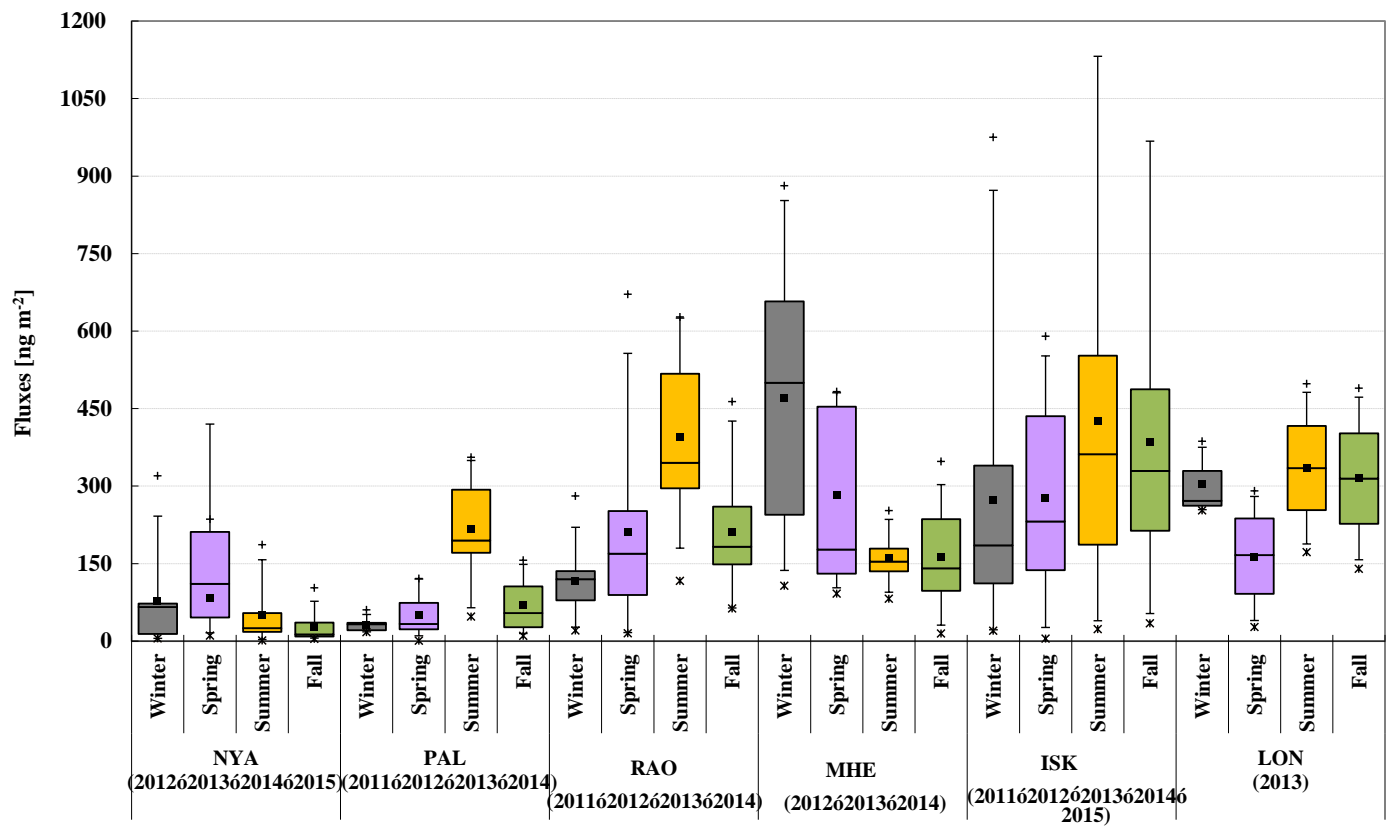

Figure 4. Seasonal distribution of sampling-weighted fluxes (by 15-day reference) at the European GMOS sites from 2011 to 2015 . Each box includes the median (midline), mean $(\mathbf{\square}), 25$ th and 75 th percentiles (box edges), 5th and 95th percentiles (whiskers), minimum $(*)$ and maximum $(+)$

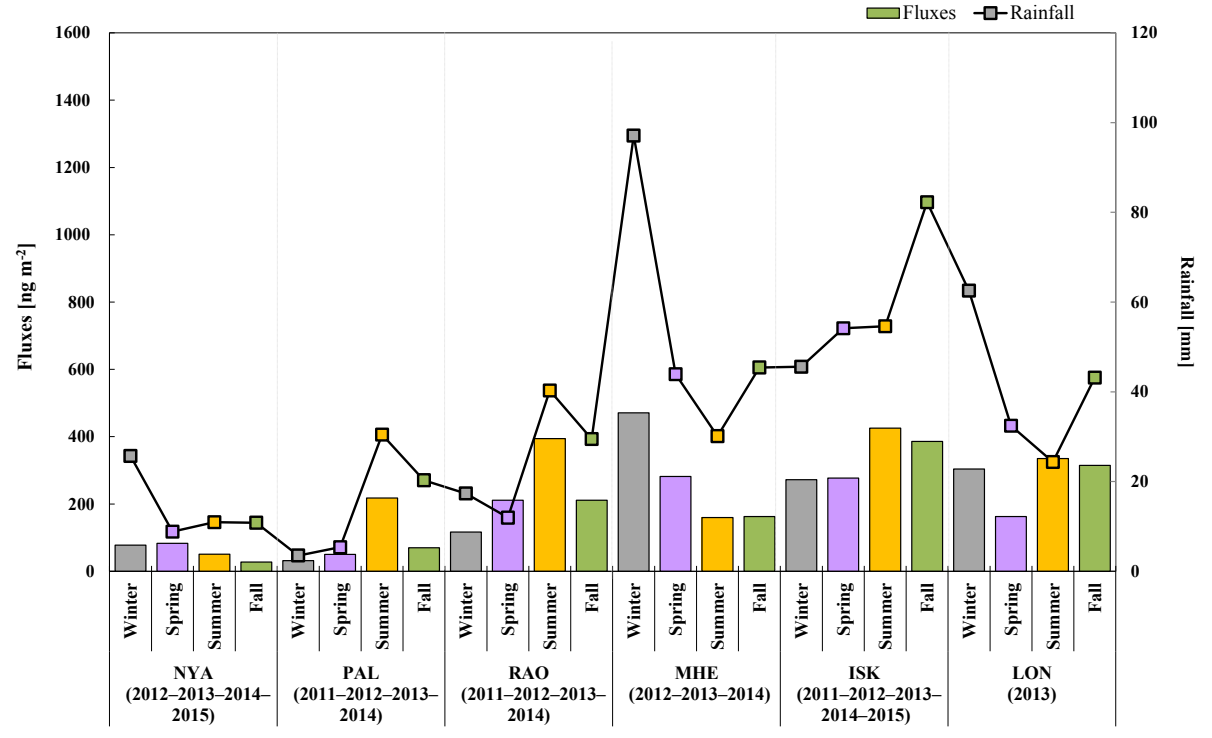

Figure 5. Seasonal mean values distribution of sampling-weighted (by 15-day reference) fluxes and rainfall at the European GMOS sites from 2011 to 2015 .

MHE, where the maximum THg wet deposition occurs during the winter. However, the patterns of $\mathrm{THg}$ concentrations and precipitation amounts reveal that, at most of the sites, the seasonal $\mathrm{THg}$ wet deposition maximum corresponds to the maximum in precipitation amounts collected, except at NYA, ISK, and LON (Fig. 5). Therefore, the dominant factor in determining the $\mathrm{Hg}$ wet deposition loading recorded at all the European sites was generally related to the amounts of precipitation collected. $\mathrm{Hg}$ concentrations in rainfall at NYA peaked in spring and decreased through the summer, fall, and winter seasons (Fig. 3). Rainfall was fairly equally distributed in all seasons except the winter season (Fig. 5). Thus, wet $\mathrm{Hg}$ loading was highest in spring, intermediate in winter and summer, and lowest in fall (Figs. 4 and 5). High levels of soluble species could in general be due to direct enhanced atmospheric oxidation of GEM to GOM, which oc- 
curs in regions with high concentrations of oxidants, such as in polar regions during springtime (where atmospheric mercury depletion events - AMDEs - such as NYA occur). At PAL, $\mathrm{Hg}$ concentrations in rainfall increased through the winter, peaking in spring, and decreased through the summer and fall (Fig. 3). Rainfall was not fairly equally distributed in all seasons but lowest values were recorded during winter and spring and highest rainfall was observed in summer (Fig. 5). Thus, wet Hg loading was highest in summer and lowest in winter (Fig. 4). Similar behavior was observed at RAO (Fig. 4), whereas at MHE, wet Hg loading was highest in winter, when also the highest rainfall amounts have been recorded, and the lowest in fall (Figs. 4 and 5). At ISK, $\mathrm{Hg}$ concentrations in rainfall and wet $\mathrm{Hg}$ loading peaked in summer and decreased in fall and winter, respectively (Figs. 3 and 4), whereas rainfall was highest in fall and lowest in winter (Fig. 5). LON shows highest seasonal THg wet deposition in summer and the lowest during spring. In this latter case, it is necessary to point out that these results are related to one year (2013) in contrast to the other sites in which all precipitation samples were grouped and analyzed season by season for a period of 3 to 5 years. Among the European sites, the highest $\mathrm{THg}$ wet deposition has been recorded at the remote RAO and PAL stations during the more photochemically active summer months, whereas lower amounts were found to be deposited in the colder months. In addition, rainfall amount during summer seems to be identified as the overriding factor controlling wet $\mathrm{Hg}$ loading at these sites. The lowest concentrations and total wet deposition were seen in winter months at most of sites. The seasonal pattern in the atmospheric $\mathrm{Hg}$, with highest precipitation concentrations and wet deposition typically seen in summer and lowest concentrations and wet deposition in winter, was believed partly to be the result of increased convection and mixing during the warmer summer months, which can increase the ability of the air to transport $\mathrm{Hg}$ over longer distances, leading to greater precipitation amounts that remove $\mathrm{Hg}$ from the atmosphere. This may also indicate the role of precipitation type in the amount of $\mathrm{Hg}$ wet deposition, as rain may have a greater capacity to scavenge and hold different forms of $\mathrm{Hg}$ than snow. Higher $\mathrm{Hg}$ deposition, typically observed during the warmer months, could be the result of a mix of meteorological source emission and atmospheric chemistry influences. For example, it is widely known that the concentrations of oxidants such as ozone, $\mathrm{OH}$ radicals, and acids that oxidize GEM to GOM are higher during warmer months and would lead to elevated concentrations of oxidized species (Schroeder and Munthe, 1998; Lin and Pehkonen, 1999). Scavenging of soluble oxidized $\mathrm{Hg}$ species has also been considered to be more efficient in summertime precipitation events than in winter due to differences in the cloud microphysical processing between rain and frozen precipitation (Hoyer et al., 1995).

\subsection{Chinese stations}

China has been regarded as one of the largest atmospheric $\mathrm{Hg}$ emission sources region in the world (Streets et al., 2005; Wu et al., 2006). However, limited monitoring sites and data are available to understand $\mathrm{Hg}$ deposition patterns in China. Few previous measurements of $\mathrm{THg}$ deposition in China have been conducted in remote areas like Mt. Fanjing (Xiao et al., 1998), Mt. Leigong (Fu et al., 2010), Wujiang River basin (Guo et al., 2008), and Mt. Gongga (Fu et al., 2008, 2010) in southwestern China, as well as at MCH (Wan et al., 2009) in northeastern China. In order to evaluate the spatial and temporal distribution of $\mathrm{THg}$ at the three GMOS Asian stations, all measurements performed from 2011 to 2014 at $\mathrm{MCH}, \mathrm{MWA}$, and MAL were grouped by season and by site (Figs. 6-8). Seasonal variations of THg in precipitation were observed at the three Chinese sites (Fig. 6). The results obtained during the sampling period were similar to the seasonal variations of THg in precipitation in other Chinese regions, such as in the Wujiang River basin, Guizhou, China, but in contrast to the observations in North America (Landis et al., 2002), the Adirondacks (Choi et al., 2008), and the Great Lakes region (Hall et al., 2005), which found increased THg concentration during summer months (Prestbo and Gay, 2009). Geographic differences in $\mathrm{Hg}$ wet deposition worldwide may be explained in part by the proximity to atmospheric sources and regional difference in anthropogenic emission sources.

Atmospheric $\mathrm{Hg}$ species, in particular GEM and PBM, have been found to be substantially increased over recent years in both remote and urban areas of China, especially in central and eastern China, compared to those observed in North America and Europe which reported opposite longterm trends (Fu et al., 2015). The increasing trend in China is possibly caused by the increase in anthropogenic $\mathrm{Hg}$ emissions in the past decade and indicates that the influence of regional emissions on $\mathrm{Hg}$ levels in China exceed global emission influence (Lindberg et al., 2007 and references therein). The seasonal variation of weighted THg concentration, observed in precipitation with the highest value in winter and lowest in summer (see Fig. 6), could be attributed in a first instance to lower rain amounts collected in winter (Fig. 8). The results obtained at the three Chinese sites show in fact that the $\mathrm{THg}$ concentrations varied with rain amount. In particular, at $\mathrm{MCH}, \mathrm{THg}$ concentrations slightly increased in autumn, peaked during the winter season, and decreased during spring and summer when the lowest values were recorded. The reverse trend has been observed in the precipitation amount, with the highest value observed in summer and the lowest in winter (Fig. 8). THg wet deposition trend is comparable to that of the precipitation amount, with values of THg flux increasing from winter and peaking in summer (Fig. 8). Ruling out the winter season at MWA during which very few rainy samples have been collected (and is thus not representative for the present discussion) weighted $\mathrm{THg}$ concentra- 


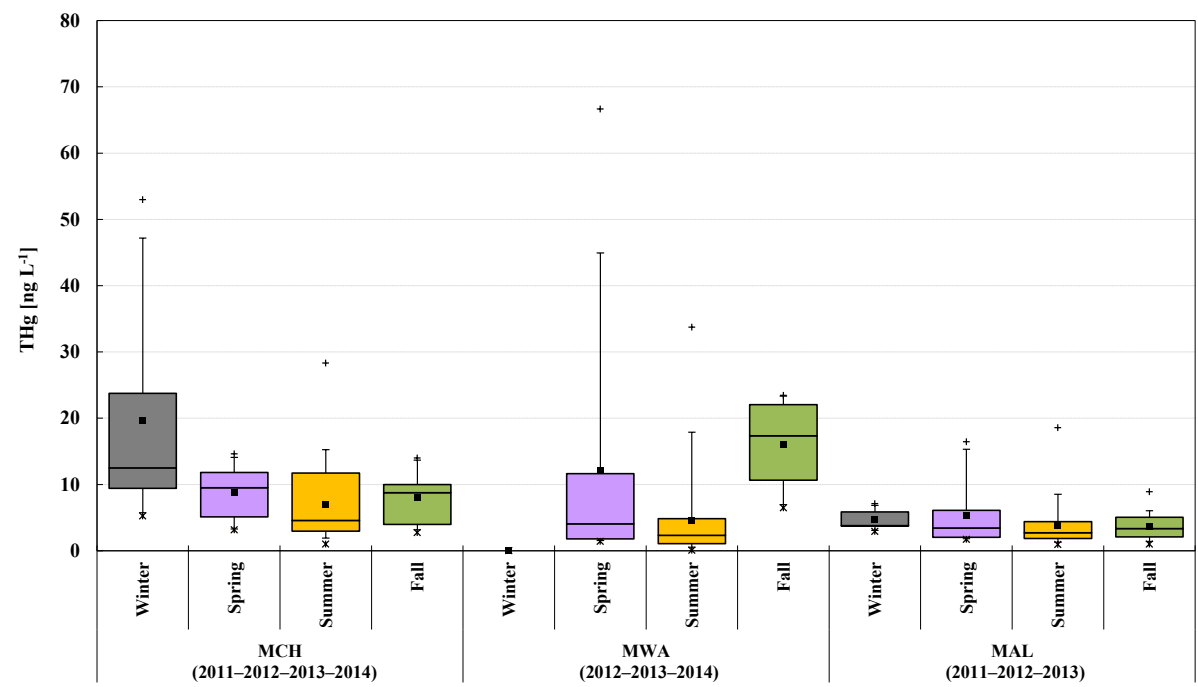

Figure 6. Seasonal distribution of volume-weighted THg concentration in precipitation at the three Chinese GMOS sites from 2011 to 2014. Each box includes the median (midline), mean (ם), 25th and 75th percentiles (box edges), 5th and 95th percentiles (whiskers), minimum $\left({ }^{*}\right)$, and maximum $(+)$.

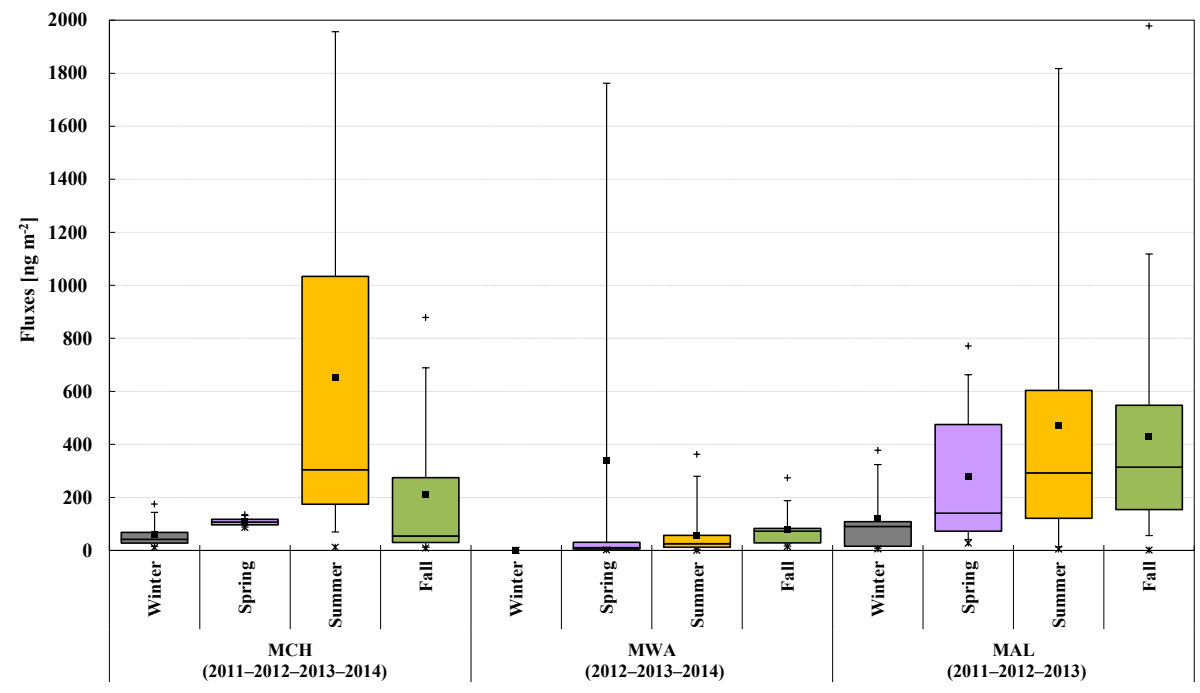

Figure 7. Seasonal distribution of sampling-weighted (by 15-day reference) fluxes at the three Chinese GMOS sites from 2011 to 2014 . Each box includes the median (midline), mean $(\mathbf{\square}), 25$ th and 75 th percentiles (box edges), 5 th and 95 th percentiles (whiskers), minimum $(*)$, and maximum $(+)$.

tions peaked in fall with lowest values in spring. Therefore, on average, wet $\mathrm{Hg}$ loading was highest in spring and lowest in summer. At MAL, the rainy samples show a fairly seasonal variability during all seasons, with the lowest rainfall in winter and the highest in summer (Fig. 8), while THg concentrations showed high values in winter and lowest in fall, and wet $\mathrm{Hg}$ loading was highest in summer, and lowest values were recorded in winter. Fu et al. (2015) highlight significant positive correlations between rainwater $\mathrm{THg}$ concentrations and $\mathrm{PBM}$ and GOM concentrations, resulting in positive correlations between wet deposition fluxes and PBM and GOM concentrations. This has been explained by the authors with the washout process of PBM and GOM during rain events which could contribute to enhancing $\mathrm{Hg}$ wet deposition in China, particularly in urban areas where PBM and GOM concentrations are much higher. Wet deposition is, in fact, commonly distinguished in terms of in-cloud and below-cloud washout and involves oxidized mercury forms (GOM, PBM). Gaseous $\mathrm{Hg}^{0}$ does not undergo direct scavenging by precipitation because of its low solubility, but it can be washed out indirectly through dissolution and oxidation in cloud water. In remote areas of China, however, washout of elevated at- 


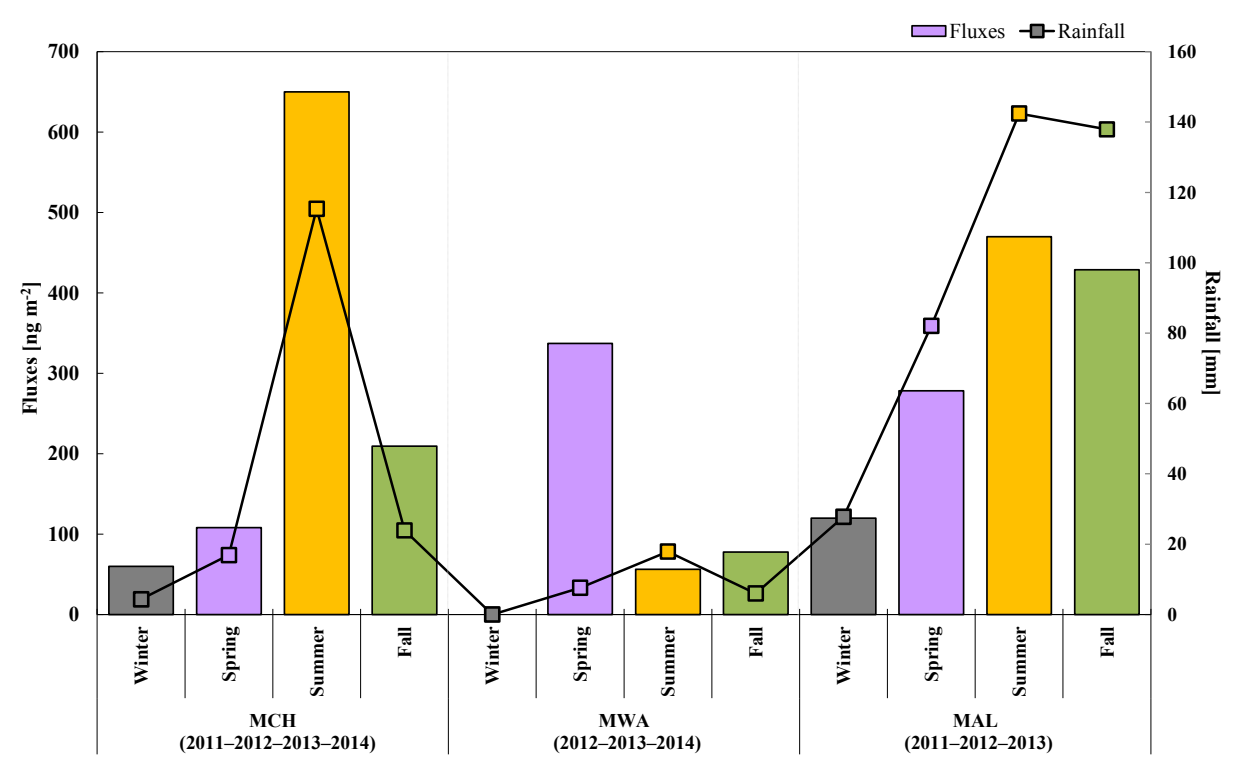

Figure 8. Seasonal mean values distribution of sampling-weighted (by 15-day reference) fluxes and rainfall at the three Chinese GMOS sites from 2011 to 2014 .

mospheric PBM does not seem to drive a notable increase in $\mathrm{Hg}$ wet deposition flux, probably due to the low washout rate of PBM during rain events at high-altitude monitoring sites, such as MAL and MWA where low-level clouds reduced the contribution of Hg washout (Lee et al., 2001; Seigneur et al., 2004). Guo et al. (2008), in a previous study in Guizhou on $\mathrm{Hg}$ in precipitation, also pointed out that maximum $\mathrm{THg}$ concentrations in rainy samples during cold seasons may be related to coal burning in domestic activities. Similar conclusions have also been reported in a study performed by Wang et al. (2012) at three Chinese sites (urban, residential and near-remote sites) in the Chongqing province from 2010 to 2011, where they also found a high correlation between $\mathrm{THg}$ and particulate $\mathrm{Hg}(\mathrm{PBM})$ concentrations, suggesting that $\mathrm{THg}$ concentration in precipitation may be influenced by the PBM concentration. Additionally, comparable seasonal behavior of $\mathrm{Hg}$ concentrations in precipitation with our results have been also observed, but with annual mean $\mathrm{THg}$ concentrations ( $\mathrm{ng} \mathrm{L}^{-1}$ ) significantly higher than those observed at the MCH, MWA, and MAL sites which are located in remote Chinese areas. The seasonal pattern in deposition flux observed at the remote MCH, MAL, and MWA are comparable with those observed at remote sites in Europe and North America (Choi et al., 2008; Mason et al., 2000; Keeler et al., 2005; Sanei et al., 2010; Lombard et al., 2011), with maximum values during warmer months. It was suggested by Keeler et al. (2005) and Mason et al. (2000) that this annual maximum was mainly due to more effective scavenging by rain in summer than by snow in the cold season (Sorensen et al., 1994; Mason et al., 2000; Keeler et al., 2005; Selin and Jacob, 2008). Hg is not incorporated into cold cloud precipitation as efficiently as it is into warm cloud precipitation (Landis et al., 2002). Other explanations for this observation have also been addressed by the authors, including a greater availability of soluble $\mathrm{Hg}$ due to convective transport in summer events (Guentzel et al., 2001; Keeler et al., 2005) and a summer increase in $\mathrm{Hg}$-containing soil-derived particles in the atmosphere (Sorensen et al., 1994).

\subsubsection{Tropical station: Sisal, Mexico}

$\mathrm{Hg}$ deposition measurements are rare in tropical latitudes, with very few scientific publications in the past decade (Shanley et al., 2015 and references therein). The tropics are a particularly important region with regard to global atmospheric chemistry. Due to intense ultraviolet radiation and high water-vapor concentrations, high $\mathrm{OH}$ concentrations oxidize inorganic and organic gases, and induce an efficient removal from the atmosphere of the oxidized products (Shanley et al., 2015 and references therein). Strong convective 


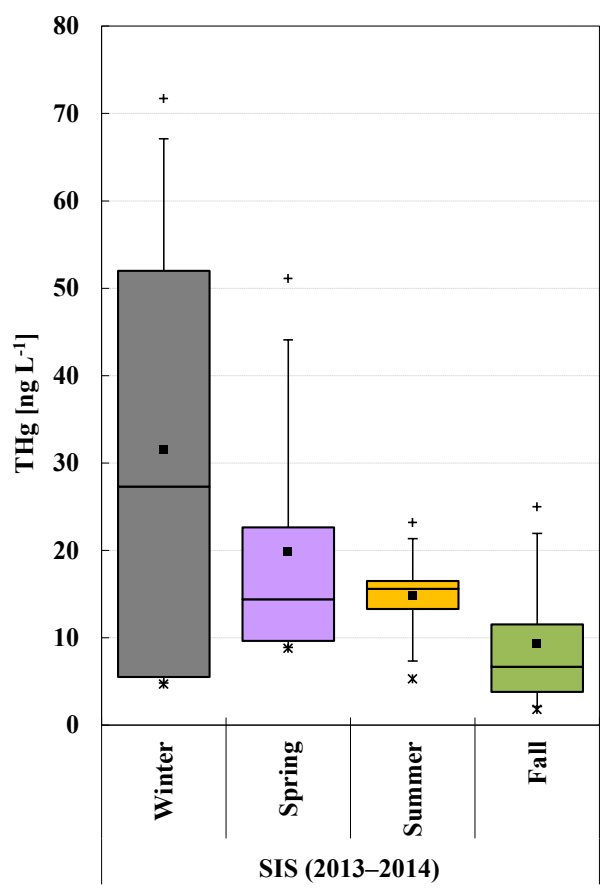

Figure 9. Seasonal distribution of volume-weighted THg concentration in precipitation at the tropical GMOS site (Sisal, Mexico) in 2013 and 2014. Each box includes the median (midline), mean (ם), 25th and 75th percentiles (box edges), 5th and 95th percentiles (whiskers), minimum $\left({ }^{*}\right)$, and maximum $(+)$.

events in the tropical regions lead to huge volumes of air being drawn out of the subcloud layer with the resultant chemical composition of the precipitation coming from the capture of gases and small particles by the liquid phases of cloud and rain. $\mathrm{Hg}$ deposition measurements started in Mexico at Celestùn station (CST) in 2012 (see Table 1), but after a short time period of sampling, the monitoring station changed the location with SIS; therefore, we refer the discussion to the SIS data related to both 2013 and 2014 during which sufficient precipitation samples have been recorded (Figs. 9-11). Despite receiving unpolluted air off the Atlantic Ocean from northeasterly and southeasterly trade winds, during most of the years (Sena et al., 2015), the site recorded higher wet $\mathrm{Hg}$ deposition fluxes during summer and fall compared to those observed during the other seasons (Fig. 10). The SIS high $\mathrm{Hg}$ deposition rates, comparable to other sites in the Northern Hemisphere, such as the Chinese sites (i.e., $\mathrm{MCH}$ ) or European sites (i.e., ISK) that sometimes are also impacted by anthropogenic emissions, are driven in part by high rainfall events more intensely during summer and fall, and less during winter and spring periods. The high wet $\mathrm{Hg}$ deposition flux at this site suggests that other tropical areas may be hotspots for $\mathrm{Hg}$ deposition as well. A number of studies have suggested that this could be due to higher precipitation and the scavenging ratios from the global pool in the subtropical free troposphere where high concentrations of oxi-

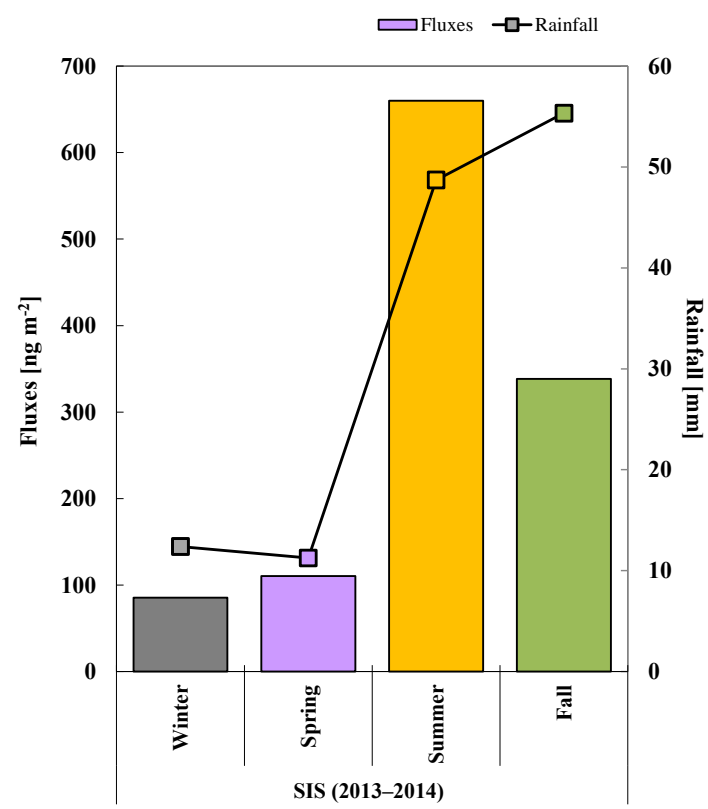

Figure 10. Seasonal distribution of sampling-weighted (by 15-day reference) fluxes at the tropical GMOS site (Sisal, Mexico) in 2013 and 2014. Each box includes the median (midline), mean (ם), 25th and 75th percentiles (box edges), 5th and 95th percentiles (whiskers), minimum $\left({ }^{*}\right)$, and maximum $(+)$.

dized Hg species exist (Guentzel et al., 2001; Seigneur et al., 2004; Selin and Jacob, 2008). These findings were also highlighted in previous studies in the south of Florida and the Gulf of Mexico coastal areas, confirming that local and regional $\mathrm{Hg}$ emissions play only a minor role in wet $\mathrm{Hg}$ deposition (Guentzel et al., 2001; Sillman et al., 2013) and suggesting that the primary source of scavenged oxidized $\mathrm{Hg}$ could be the global pool.

Weather patterns in SIS exhibit a seasonality in annual rainfall, with highest rainfall from June/July through October/November. Summer tropical waves and systems characterized by deep convection and low pressure produced greater rainfall. During summer and fall, the site indeed receives rainfall from deep convection associated with tropical waves embedded in the prevailing easterly airflow. THg concentrations were higher in low volume samples. With larger storms, $\mathrm{Hg}$ concentrations were diluted; this means that rainout of $\mathrm{Hg}$ was maximum (the decreasing of $\mathrm{Hg}$ concentrations with the increasing of the rainfall depth). Weighted $\mathrm{THg}$ concentrations in rainfall $\left(\mathrm{ng} \mathrm{L}^{-1}\right)$ peaked in winter and decreased through the spring and summer (Fig. 9). THg in wet deposition was highest in summer and lowest in spring and winter (Fig. 10). The higher summer $\mathrm{Hg}$ deposition flux is not driven by higher $\mathrm{Hg}$ concentrations in rainfall since the highest $\mathrm{Hg}$ concentrations in rain samples occurred in winter. Different mechanisms leading to enhanced $\mathrm{Hg}$ concentrations in rain during the winter, including greater anthropogenic emissions, are probably associated with higher use 


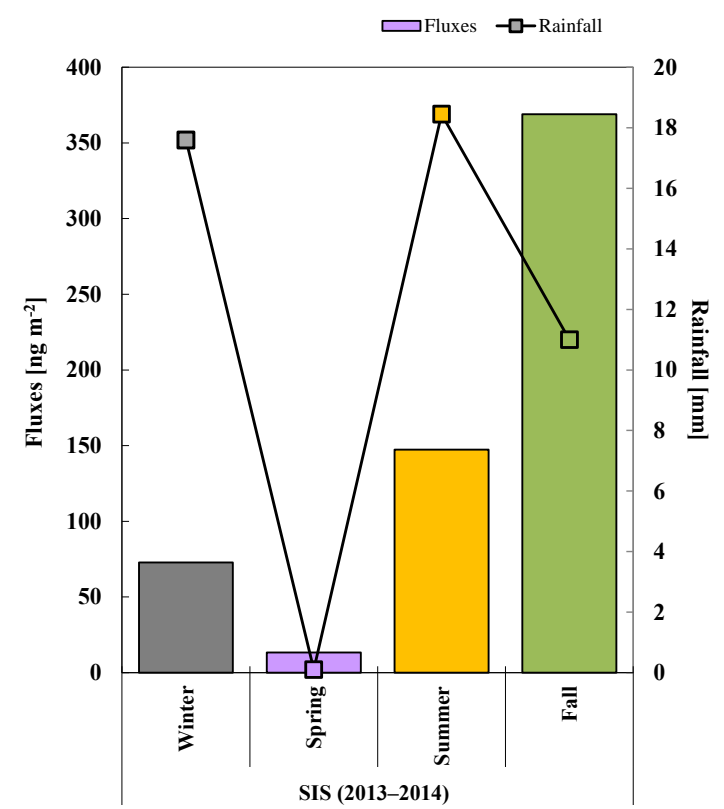

Figure 11. Seasonal mean values distribution of sampling-weighted (by 15-day reference) fluxes and rainfall at the tropical GMOS site (Sisal, Mexico) in 2013 and 2014.

of fossil fuels in power plants during the cold season. As reported in Sect. 3, relating to the annual wet deposition patterns, the THg wet deposition observed at SIS could also be influenced by air masses crossing particularly in winter the southern United States and southern Florida where several coal power plants and waste incinerators (Latysh and Wetherbee, 2007) are located. The high wet deposition of $\mathrm{Hg}$ during the rainy seasons (May/June to October/November), in contrast, could be due to more efficient scavenging processes of reactive gaseous mercury from the free troposphere by tall convective thunderstorms, and the concentration of GOM by the sea breeze effect, where the diurnal alternation of onshore and offshore winds can lead to a buildup of pollutants in the air mass. Greater information on $\mathrm{Hg}$ deposition and cycling is needed in tropical regions, where populations are more likely to be exposed to $\mathrm{Hg}$ through fish consumption and artisanal gold mining activity.

\subsubsection{Southern Hemisphere stations}

In remote areas far from any local sources, atmospheric deposition has been recognized as the main source of $\mathrm{Hg}$ to the ocean (Lindberg et al., 2007; Pirrone et al., 2008). Hg can then be re-emitted back to the atmosphere via gas exchange, and modeling studies suggest that re-emission from oceans is a major contributor to atmospheric concentrations of GEM, particularly in the Southern Hemisphere where oceans were shown to contribute more than half of the surface atmospheric concentration (Strode et al., 2007 and references therein). In the Southern Hemisphere, we considered the four monitoring sites, AMS, CPT, CGR, and BAR, which recorded a representative number of samples over the 20122015 period. Figures 12 and 13 show the box plots related to rainfall, $\mathrm{THg}$ concentrations in precipitation, as well as wet deposition flux of $\mathrm{Hg}$ recorded, whereas Fig. 14 shows the mean values of rainfall amounts with the corresponding mean values of $\mathrm{Hg}$ fluxes at the four southern sites. An NSA171 (Eigenbrodt) collector was set up at AMS at the beginning of the 2013. The GMOS site experienced a mild oceanic climate with monthly median air temperature ranging from $11^{\circ} \mathrm{C}$ in austral winter to $17^{\circ} \mathrm{C}$ in austral summer and frequent presence of clouds (Sciare et al., 2009). In 2013 and 2014, AMS displayed a seasonal variation of the precipitation amounts, with the highest values collected during the winter season (Fig. 14). On the contrary, the THg wet deposition flux patterns did not show a similar variation throughout the seasons as well as the THg concentrations in precipitation samples (Figs. 12 and 13). At CPT, the Hg concentrations in precipitation, $\mathrm{Hg}$ wet deposition fluxes as well as the precipitation amounts, followed the same trend during the rainy season (May-October), with a maximum in wintertime for all the parameters recorded. CPT experiences a Mediterranean-type climate that is characterized by rather dry summers comprising moderate temperatures. The austral autumn to spring season normally experiences increased precipitation due to the passage of cold fronts moving from west to east; therefore, CPT generally receives clean marine air from the Atlantic Ocean, whereas continental and polluted air masses are observed at the site more frequently, mainly during the winter period (Brunke et al., 2004, 2016), due to the prevailing air masses from the north to northwestern sector (Rautenbach and Smith, 2001; Brunke et al., 2004). The highest THg concentrations and wet deposition fluxes recorded during the winter season could be due also to the contribution of polluted air masses crossing the Cape Town metropolitan area before arriving at the stations. However, a more recent study on GEM concentrations and THg in precipitation carried out by Brunke et al. (2016) over a period of 7 years (2007-2013) highlighted that GEM, THg, CO, and ${ }^{222} \mathrm{Rn}$ levels within the urban-marine events observed at CPT did not substantially differ from those seen in the marine rain episodes, concluding that no significant local anthropogenic influences were detected on $\mathrm{THg}$ concentrations. Conversely, a significant positive correlation was found at CPT between GEM and THg concentrations, and with the Southern Oscillation Index (SOI), suggesting that both GEM and THg concentrations are primarily influenced by large-scale meteorology which in turn controls $\mathrm{Hg}$ emission sources in terms, for example, of enhanced sea surface temperature that could increase large-scale droughts leading to raised biomass burning (Brunke et al., 2016).

Measurements of atmospheric $\mathrm{Hg}$ deposition in Australia have never been reported before (Jardine and Bunn, 2010). From 2013 to 2015, at the CGR GAW station, located on the northwestern coast of Tasmania, Australia, highest value 


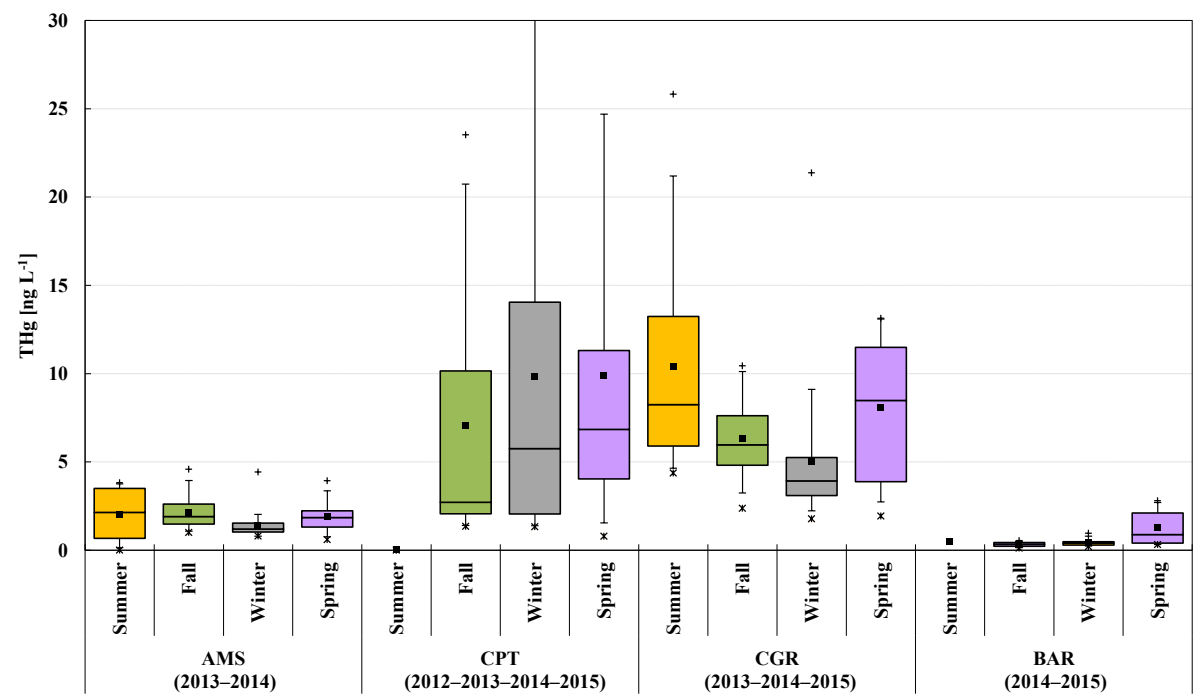

Figure 12. Seasonal distribution of volume-weighted THg concentration in precipitation at the four GMOS sites in the Southern Hemisphere from 2012 to 2015 . Each box includes the median (midline), mean ( $\boldsymbol{\square}), 25$ th and 75 th percentiles (box edges), 5th and 95th percentiles (whiskers), minimum $(*)$, and maximum $(+)$.

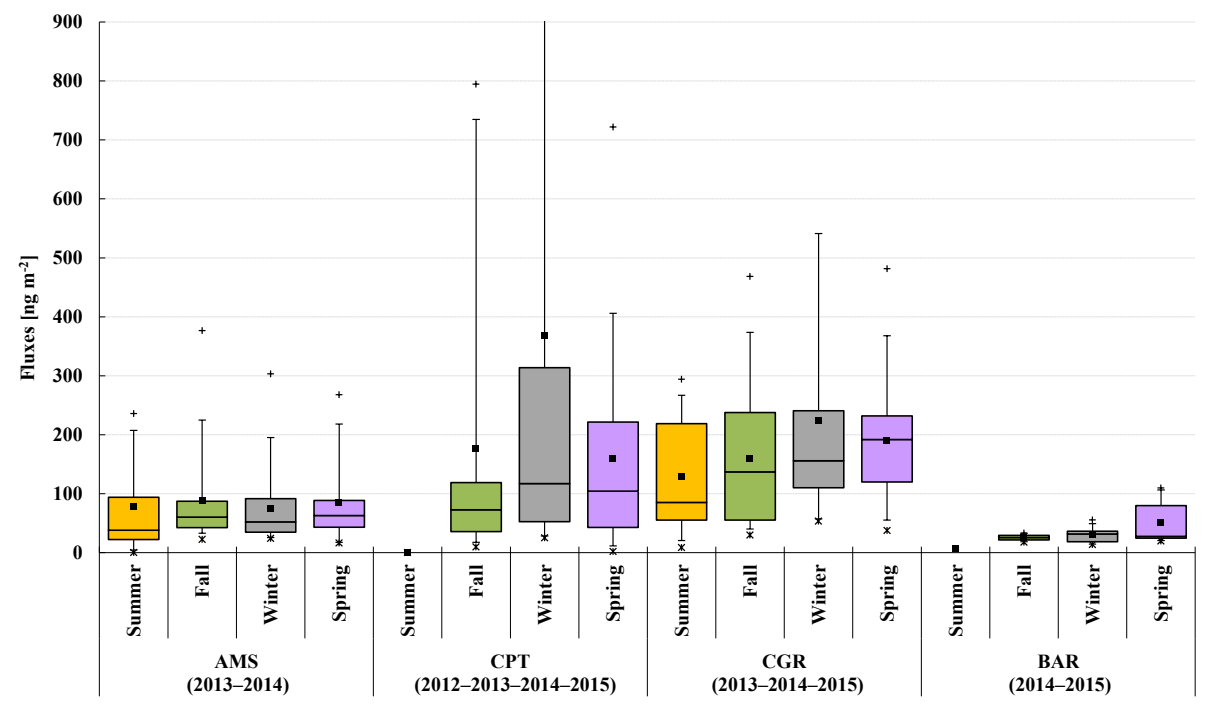

Figure 13. Seasonal distribution of sampling-weighted (by 15-day reference) fluxes at the four GMOS sites in the Southern Hemisphere from 2012 to 2015. Each box includes the median (midline), mean (ם), 25th and 75th percentiles (box edges), 5th and 95th percentiles (whiskers), minimum $\left(^{*}\right)$, and maximum $(+)$.

in rainfall have been observed during winter an lowest in summer, whereas Hg concentrations peaked in summer and dropped to lowest values in winter (see Figs. 12 and 14). Indeed, an increase in precipitation volume results in a decrease in $\mathrm{Hg}$ concentrations in rain, probably due to the dilution of the washout loading (Prestbo and Gay, 2009). This means that any change in meteorological conditions, especially precipitation, complicates the interpretation of GMOS observations at different latitudes and might mask any trends due to changes in $\mathrm{Hg}$ emissions. The trend of $\mathrm{Hg}$ wet deposition fluxes shows a seasonal variability with highest values in spring and lowest in cold seasons. At BAR, the highest precipitation amounts in 2014 and 2015 were collected during the fall and winter seasons and decreased in spring when the highest THg concentrations occurred (see Figs. 12 and 14). Therefore, the seasonal THg wet deposition peaked in spring and decreased during the cold seasons (Fig. 13). It is necessary to point out, however, that in both 2014 and 2015 at BAR very few samples have been recorded in fall and summer (Tables S1-S4). This means that further measurements and studies are needed to draw any conclusion and improve our understanding of deposition processes and oxidation mech- 


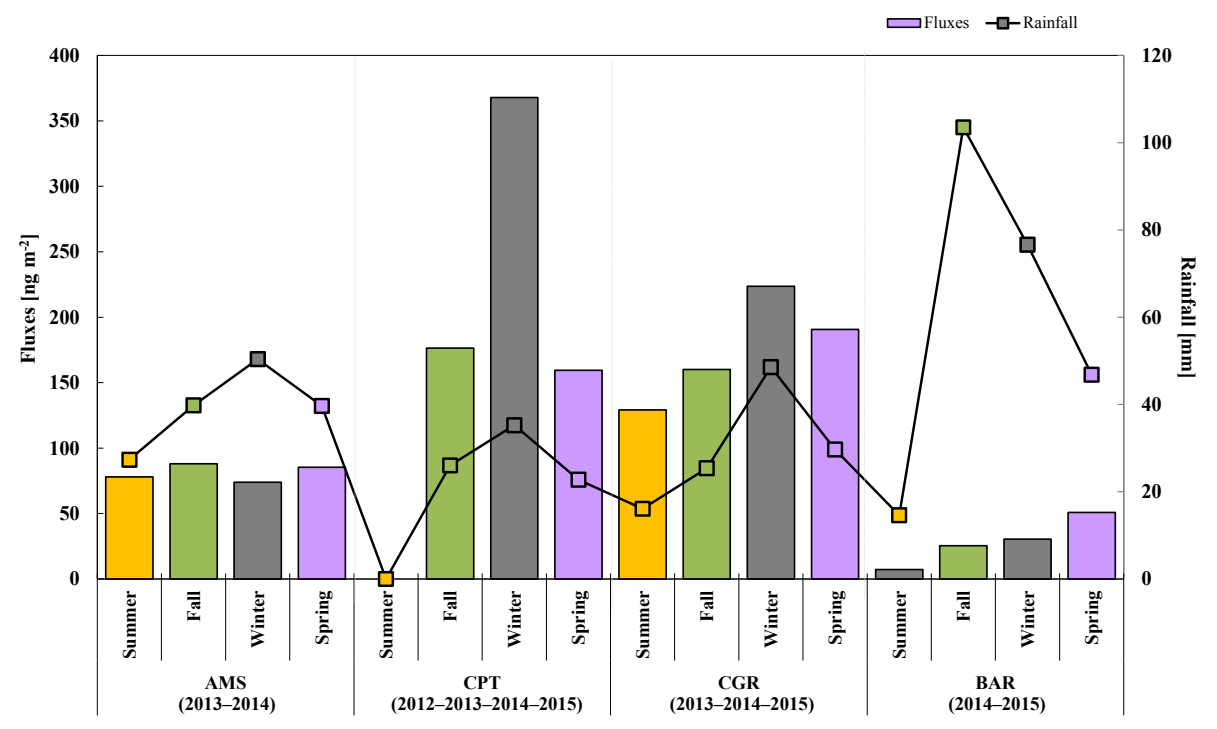

Figure 14. Seasonal mean values distribution of sampling-weighted (by 15-day reference) fluxes and rainfall at the four GMOS sites in the Southern Hemisphere from 2012 to 2015.

anisms in this region. There are very few previous observations of $\mathrm{Hg}$ wet deposition in the Southern Hemisphere, and this makes difficult any comparison of data recorded during GMOS. The results observed at the four southern GMOS sites highlighted that the magnitude of wet deposition is affected by two main factors: amount of precipitation and the $\mathrm{THg}$ concentration in precipitation influenced by soluble $\mathrm{Hg}$ species (oxidized $\mathrm{Hg}$ ) in the atmosphere. High levels of soluble species could in general be due to direct anthropogenic emissions of $\mathrm{Hg}$ oxidized species or by enhanced atmospheric oxidation of GEM to GOM, which occurs in regions with high concentrations of oxidants such as southern locations (where more solar radiation occurs) or polar regions during springtime (where AMDEs occur).

\section{Conclusions}

Mercury deposition measurements are critical for constructing an accurate global $\mathrm{Hg}$ budget and modeling the benefits or consequences of changes in $\mathrm{Hg}$ emissions, for example, as prescribed by the Minamata Convention. The scarce availability of long-term wet $\mathrm{Hg}$ deposition data for calibration or validation of models could cause uncertainties in modeling applications to assess the influence of local emission sources. A synthesis of available $\mathrm{Hg}$ measurements in precipitation from selected GMOS ground-based sites is presented, including trends and seasonal cycles. Wet deposition samples were collected for approximately 5 years, from 2011 to 2015, at 17 selected GMOS monitoring sites located in the Northern and Southern hemispheres, as well as in the tropical area. In the Northern Hemisphere, and specifically at the European stations, a geographical trend with an increase in
THg wet deposition from north to south has been observed. These findings are in good agreement with the geographical distribution of atmospheric $\mathrm{Hg}$ data obtained during the same period within the GMOS network with a downward gradient from the Northern to the Southern Hemisphere. At the other GMOS monitoring sites in the Northern Hemisphere (i.e., Chinese sites), as well as those at lower latitude (i.e., tropical area and Southern Hemisphere) no north-south spatial trend has conversely been observed. Annual and seasonal patterns in $\mathrm{Hg}$ wet deposition are clearly evident at all GMOS sites, implying a significant dependence on meteorological conditions throughout the years. Most of the ground-based sites report, in particular, $\mathrm{Hg}$ deposition strongly influenced by the precipitation amounts. In the Northern Hemisphere, interannual differences in THg wet deposition are mostly linked with precipitation volume, with the greatest deposition flux occurring in the wettest years, whereas at the sites located at lower latitude and in the Southern Hemisphere the relationship between precipitation amount and deposition was not as evident as in the north. It is however necessary to point out the need to expand the global network particularly in the tropics and Southern Hemisphere regions in order to provide more information throughout long-term monitoring activities. As a starting point of a global network, these results provide a set of data for modeling applications to fully understand THg wet deposition patterns as well as the transformation and deposition mechanisms of atmospheric $\mathrm{Hg}$. With broad geographic coverage, including background and remote sites as well as local or regional sources, GMOS's observation network gives important insights to modeling applications to evaluate future $\mathrm{Hg}$ trends and their fate and transport on a global scale. The results of THg wet deposition carried out in this study open the way for new avenues 
in future modeling studies as well as highlight the need for additional and integrated measurements in ambient air and rainwater samples to improve our understanding of deposition processes and oxidation mechanisms. These new observations, in fact, give scientists and modelers some insight into baseline concentrations of THg concentrations in precipitation and depositional fluxes especially in the tropical area, and in the Southern Hemisphere where wet deposition as well as atmospheric $\mathrm{Hg}$ species were not investigated before. Greater information on $\mathrm{Hg}$ deposition and cycling is obviously needed in these regions. Moving forward, in addition to continued monitoring GMOS sites, integration with other ground-based monitoring sites at strategic locations, along with integrations with atmospheric $\mathrm{Hg}$ species and other key oxidants, and identification of the compounds making up GOM and $\mathrm{PBM}_{2.5}$ continue to be needed. Knowledge of these exact chemical species would also lead to improved understanding of the chemistry and wet and dry deposition processes of oxidized $\mathrm{Hg}$ species in different air masses. These and other uncertainties are the subject of ongoing research. The magnitude of $\mathrm{Hg}$ dry deposition is to date uncertain, especially dry deposition of GEM, and few measurements are available to constrain model estimates. Further measurements of dry deposition, especially in locations where wet deposition measurements are available, would dramatically improve scientific understanding of the $\mathrm{Hg}$ cycle. Wet deposition measurements worldwide would assist modelers in constraining the atmospheric $\mathrm{Hg}$ budget on a global scale, as would additional direct measurements of dry deposition across the GMOS network.

\section{Data availability}

Mercury data discussed in this paper are reported within the GMOS central database and are available upon request at http://sdi.iia.cnr.it/geoint/publicpage/GMOS.

\section{The Supplement related to this article is available online at doi:10.5194/acp-17-2689-2017-supplement.}

Competing interests. The authors declare that they have no conflict of interest.

Acknowledgements. This work was funded by the FP7 (20102015) Global Mercury Observation System (GMOS) project. We thank all GMOS external partners for providing high-quality controlled wet deposition measurements as well as all the site operators for the GMOS global network. Aurélien Dommergue, Olivier Magand, and Helene Angot thank the French Polar Institute IPEV (program 1028, GMOStral), the LEFE CNRS/INSU (program SAMOA), and the overwintering crew at Amsterdam Island. The CNR-IIA research staff also thanks F. Cofone, A. Servidio, and A. Rosselli for their technical support for the laboratory work carried out on the samples from AMS, LON, CMA, and the Mexican stations.

Edited by: A. Dastoor

Reviewed by: M. Cohen and two anonymous referees

\section{References}

1631 U. E. M.: Revision E, Mercury in water by Oxidation, Purge and Trap, and Cold Vapor atomic Fluorescence Spectrometry, Tech. rep., United States Environmental Protection Agency, Washington, 2002.

Angot, H., Barret, M., Magand, O., Ramonet, M., and Dommergue, A.: A 2-year record of atmospheric mercury species at a background Southern Hemisphere station on Amsterdam Island, Atmos. Chem. Phys., 14, 11461-11473, doi:10.5194/acp14-11461-2014, 2014.

Brown, R., Pirrone, N., van Hoek, C., Horvat, M., Kotnik, J., Wangberg, I., Corns, W., Bieber, E., and Sprovieri, F.: Standardization of a European measurement method for the determination of total gaseous mercury: results of the field trial campaign and determination of a measurement uncertainty and working range, Accred. Qual. Assur., 15, 359-366, doi:10.1007/s00769-010-06362, 2010a.

Brown, R., Pirrone, N., van Hoek, C., Sprovieri, F., Fernandez, R., and Toté, K.: Standardisation of a European measurement method for the determination of mercury in deposition: results of the field trial campaign and determination of a measurement, J. Environ. Monit., 12, 689-695, doi:10.1039/b924955a, 2010b.

Brunke, E., Labuschagne, C., Parker, B., Scheel, H., and Whittlestone, S.: Baseline air mass selection at Cape Point, South Africa: application of ${ }^{222} \mathrm{Rn}$ and other filter criteria to $\mathrm{CO}_{2}$, Atmos. Environ., 38, 5693-5702, doi:10.1016/j.atmosenv.2004.04.024, 2004.

Brunke, E., Walters, C., Mkololo, T., Martin, L., Labuschagne, C., Silwana, B., Slemr, F., Weigelt, A., Ebinghaus, R., and Somerset, V.: Somerset Mercury in the atmosphere and in rainwater at Cape Point, S. Afr. Atmos. Environ., 125, 24-32, 2016.

Chazin, J. D., Allen, M. K., and Rodger, B. C.: Measurement of mercury deposition using passive samplers based on the Swedish (IVL) design, Atmos. Environ., 29, 1201-1209, doi:10.1016/1352-2310(94)00335-I, 1995.

Chen, L., Wang, H. H., Liu, J. F., Tong, Y. D., Ou, L. B., Zhang, W., Hu, D., Chen, C., and Wang, X. J.: Intercontinental transport and deposition patterns of atmospheric mercury from anthropogenic emissions, Atmos. Chem. Phys., 14, 10163-10176, doi:10.5194/acp-14-10163-2014, 2014.

Choi, H.-D., Sharac, T. J., and Holsen, T. M.: Mercury deposition in the Adirondacks: A comparison between precipitation and throughfall, Atmos. Environ., 42, 1818-1827, 2008.

Dabrowski, J., Ashton, P., Murray, K., Leaner, J., and Mason, R.: Anthropogenic mercury emissions in South Africa: coal combustion in power plants, Atmos. Environ., 42, 6620-6626, 2008.

Diéguez, M., García, P., and Sprovieri, F.: Atmospheric mercury fluxes in North Patagonia: first continuous records of the EMMA station (Global Mercury Observation System, Bariloche, Argentina), in: 12th International Conference on Mercury as a 
Global Pollutant (ICMGP), 14-19 June 2015, Jeju, Republic of Korea, 2015.

Driscoll, C., Mason, R., Chan, H., Jacob, D., and Pirrone, N.: Mercury as a global pollutant: sources, pathways, and effects, Environ. Sci. Technol., 47, 4967-4983, doi:10.1021/es305071v, 2013

Fu, X., Feng, X., and Wang, S.: Exchange fluxes of Hg between surfaces and atmosphere in the eastern flank of Mount Gongga, Sichuan province, southwestern China, J. Geophys. Res., 23, 408-418, doi:10.1029/2008JD009814, 2008.

Fu, X., Feng, X., Dong, Z., Yin, R., Wang, J., Yang, Z., and Zhang, H.: Atmospheric gaseous elemental mercury (GEM) concentrations and mercury depositions at a high-altitude mountain peak in south China, Atmos. Chem. Phys., 10, 2425-2437, doi:10.5194/acp-10-2425-2010, 2010.

Fu, X., Zhang, H., Yu, B., Wang, X., Lin, C., and Feng, X.: Observations of atmospheric mercury in China: a critical review, Atmos. Chem. Phys., 15, 9455-9476, doi:10.5194/acp-15-94552015, 2015.

Fu, X. W., Feng, X., Dong, Z. Q., Yin, R. S., Wang, J. X., Yang, Z. R., and Zhang, H.: Atmospheric gaseous elemental mercury GEM) concentrations and mercury depositions at a high-altitude mountain peak in south China, Atmos. Chem. Phys., 10, 2425 2437, doi:10.5194/acp-10-2425-2010, 2010.

Gay, D. A., Schmeltz, D., Prestbo, E., Olson, M., Sharac, T., and Tordon, R.: The Atmospheric Mercury Network: measurement and initial examination of an ongoing atmospheric mercury record across North America, Atmos. Chem. Phys., 13, 1133911349, doi:10.5194/acp-13-11339-2013, 2013.

Gratz, L. E., Keeler, G. J., and Miller, E. K.: Long-term relationships between mercury wet deposition and meteorology, Atmos. Environ., 43, 6218-6229, 2009.

Guentzel, J. L., Landing, W. M., Gill, G. A., and Pollman, C. D.: Processes Influencing Rainfall Deposition of Mercury in Florida, Environ. Sci. Technol., 35, 863-873, 2001.

Guo, Y., Feng, X., Li, Z., He, T., Yan, H., Meng, B., Zhang, J., and Qiu, G.: Distribution and wet deposition fluxes of total and methyl mercury in Wujiang River basin, Guizhou, China, Atmos. Environ., 42, 7096-7103, 2008.

Hall, B. D., Manolopoulos, H., Hurley, J. P., Schauer, J. J., St. Louis, V. L., Kenski, D., Graydon, J., Babiarz, C. L., Cleckner, L. B., and Keeler, G. J.: Methyl and total mercury in precipitation in the Great Lakes region, Atmos. Environ., 39, 7557-7569, 2005.

Hansen, A. and Gay, D.: Observations of mercury wet deposition in Mexico, Environ. Sci. Pollut. Res., 20, 8316-8325, doi:10.1007/s11356-013-2012-3, 2013.

Holmes, C. D., Jacob, D. J., Mason, R. P., and Jaffe, D. A.: Sources and deposition of reactive gaseous mercury in the marine atmosphere, Atmos. Environ., 43, 2278-2285, 2009.

Holmes, C. D., Jacob, D. J., Corbitt, E. S., Mao, J., Yang, X., Talbot, R., and Slemr, F.: Global atmospheric model for mercury including oxidation by bromine atoms, Atmos. Chem. Phys., 10, 12037-12057, doi:10.5194/acp-10-12037-2010, 2010.

Hoyer, M., Burke, J., and Keeler, G.: Atmospheric sources, transport and deposition of mercury inMichigan: two years if event precipitation, Water Air Soil Pollut., 80, 199-208, 1995.

Hylander, L.: Global mercury pollution and its expected decrease after a mercury trade ban, Water Air Soil Pollut., 125, 334-334, 2001.
Iverfeldt, A.: Mercury in forest canopy through fall water and its relation to atmospheric deposition, Water Air and Soil Pollut., 56, 553-564, 1991.

Jardine, T. D. and Bunn, S. E.: Northern Australia, whither the mercury?, CSIRO, Mar. Freshwater Res., 61, 451-463, doi:10.1071/MF09126, 2010.

Keeler, G., Gratz, L., and Al-wali, K.: Long-term Atmospheric Mercury Wet Deposition at Underhill, Vermont, Ecotoxicology, 14, 71-83, 2005.

Landis, M., Stevens, R., Schaedlich, F., and Prestbo, E.: Development and characterization of an annular denuder methodology for the measurement of divalent inorganic reactive gaseous mercury in ambient air, Environ. Sci. Technol., 36, 3000-3009, doi:10.1021/es015887t, 2002.

Landis, M. S. and Keeler, G. J.: Critical evaluation of a modified automatic wet-only precipitation collector for mercury and trace element determinations, Environ. Sci. Technol., 31, 2610-2615, doi:10.1021/Es9700055, 1997.

Latysh, N. E. and Wetherbee, G. A.: NADP-MDN Report: External Quality Assurance Programs Managed by the U.S. Geological Survey in Support of the National Atmospheric Deposition Program/Mercury Deposition Network, Tech. rep., United States Geological Survey (USGS) and US Department of the Interior, Reston, Virginia, 2007.

Lee, D. S., Nemitz, E., Fowler, D., and Kingdon, R. D.: Modelling atmospheric mercury transport and deposition across Europe and the UK, Atmos. Environ., 35, 5455-5466, doi:10.1016/S13522310(01)00284-9, 2001.

Lin, C. and Pehkonen, S.: The chemistry of atmospheric mercury: a review, Atmos. Environ., 33, 2067-2079, 1999.

Lindberg, S., Brooks, S., Lin, C., Scott, K., Landis, M., Stevens, R., and Goodsite, M.: Dynamic oxidation of gaseous mercury in the arctic troposphere at polar sunrise, Environ. Sci. Technol., 36, 1245-1256, 2002.

Lindberg, S., Bullock, R., Ebinghaus, R., Engstrom, D., Feng, X., Fitzgerald, W., Pirrone, N., Prestbo, E., and Seigneur, C.: A synthesis of progress and uncertainties in attributing the sources of mercury in deposition, AMBIO, 36, 19-33, 2007.

Lombard, M. A. S., Bryce, J. G., Mao, H., and Talbot, R.: Mercury deposition in Southern New Hampshire, 2006-2009, Atmos. Chem. Phys., 11, 7657-7668, doi:10.5194/acp-11-76572011, 2011.

Mason, R. and Sheu, G.: Role of the ocean in the global mercury cycle, Global Biogeochem. Cy., 16, 1093 , doi:10.1029/2001gb001440, 2002.

Mason, R., Lawson, N., and Sheu, G.: Annual and seasonal trends in mercury deposition in Maryland, Atmos. Environ., 34, 16911701, doi:10.1016/S1352-2310(99)00428-8, 2000.

Mason, R., Choi, A., Fitzgerald, W., Hammerschmidt, C., Soerensen, C. L. A., and Sunderland, E.: Mercury Biogeochemical Cycling in the Ocean and Policy Implications, Global Biogeochem. Cy., 119, 101-117, 2012.

Munthe, J., Wangberg, I., Iverfeldt, A., Lindqvist, O., Stomberg, D., Sommar, J., Gårdfeldt, K., Petersen, G., Ebinghaus, R., Prestbo, E., Larjava, K., and Siemens, V.: Distribution of atmospheric mercury species in Northern Europe: final results from the MOE project, Atmos. Environ., 37, 9-20, 2003.

Munthe, J., Wängberg, I., Rognerud, S., Fjeld, E., Verta, M., Porvari, P., and Meili, M.: Mercury in Nordic Ecosystem, Tech. rep., 
IVL Report B1761, IVL Swedish Environmental Research Institute Ltd., Göteborg, Sweden, 2007.

Munthe, J., Sprovieri, F., Horvat, M., and Ebinghaus, R.: SOPs and QA/QC protocols regarding measurements of TGM, GEM, RGM, TPM and mercury in precipitation in cooperation with WP3, WP4 and WP5, GMOS deliverable 6.1, CNR-IIA, IVL, available at: http://www.gmos.eu (last access: February 2017), 2011.

Nair, U. S., Wu, Y., Holmes, C. D., Ter Schure, A., Kallos, G., and Walters, J. T.: Cloud-resolving simulations of mercury scavenging and deposition in thunderstorms, Atmos. Chem. Phys., 13, 10143-10157, doi:10.5194/acp-13-10143-2013, 2013.

Pacyna, E., Pacyna, J., Sundseth, K., Munthe, J., Kindbom, K., Wilson, S., Steenhuisen, F., and Maxson, P.: Global emission of mercury to the atmosphere from anthropogenic sources in 2005 and projections to 2020, Atmos. Environ., 44, 24872499, doi:10.1016/j.atmosenv.2009.06.009, 2010.

Pirrone, N., Hedgecock, I., and Sprovieri, F.: Atmospheric mercury, easy to spot and hard to pin down: impasse?, Atmos. Environ., 42, 8549-8551, doi:10.1016/j.atmosenv.2008.09.004, 2008.

Pirrone, N., Cinnirella, S., Feng, X., Finkelman, R., Friedli, H., Leaner, J., Mason, R., Mukherjee, A., Stracher, G., Streets, D., and Telmer, K.: Global mercury emissions to the atmosphere from anthropogenic and natural sources, Atmos. Chem. Phys, 10, 5951-5964, doi:10.5194/acp-10-5951-2010, 2010.

Prestbo, E. M. and Gay, D. A.: Wet deposition of mercury in the U.S. and Canada, 1996-2005: Results and analysis of the NADP mercury deposition network (MDN), Atmos. Environ., 43, 42234233, 2009.

Rautenbach, C. D. and Smith, I.: Teleconnections between global sea-surface temperatures and the interannual variablility of observed and model simulated rainfall over southern Africa, J. Hydrol., 254, 1-15, 2001.

Sanei, H., Outridge, P., Goodarzi, F., Wang, F., Armstrong, D., Warren, K., and Fishback, L.: Wet deposition mercury fluxes in the Canadian sub-Arctic and southern Alberta, measured using an automated precipitation collector adapted to cold regions, Atmos. Environ., 44, 1672-1681, 2010.

Schroeder, W. and Munthe, J.: Atmospheric mercury - An overview, Atmos. Environ., 32, 809-822, doi:10.1016/S13522310(97)00293-8, 1998.

Sciare, J., Favez, O., Sarda-Estève, R., Oikonomou, K., Cachier, H., and Kazan, V.: Long-term observations of carbonaceous aerosols in the austral ocean atmosphere: evidence of a biogenic marine organic source, J. Geophys. Res., 114, D15302, doi:10.1029/2009JD011998, 2009.

Seigneur, C., Vijayaraghavan, K., Lohman, K., Karamchandani, P., and Scott, C.: Global Source Attribution for Mercury Deposition in the United States, Environ. Sci. Technol., 38, 555-569, 2004.

Selin, N. E.: Global Biogeochemical Cycling of Mercury: A Review, Annu. Rev. Environ. Resour., 34, 43-63, 2009.

Selin, N. E.: Global change and mercury cycling: Challenges for implementing a global mercury treaty, Environ. Toxicol. Chem., 33, 1202-1210, doi:10.1002/etc.2374, 2014.

Selin, N. E. and Jacob, D. J.: Seasonal and spatial patterns of mercury wet deposition in the United States: Constraints on the contribution from North American anthropogenic sources, Atmos. Environ., 42, 5193-5204, 2008.
Sena, F., Umlauf, G., Ruiz, A. A., Islas, M. R., Trejo, J. A. V., Cabrera, F. A., and Vargas, I. O.: Wet deposition and atmospheric mercury monitoring in Sisal, Yucatán, México, as part of the Global Mercury Observation System (GMOS), Tech. rep., JRC - European Commision, doi:10.2788/823558, 2015.

Sexauer Gustin, M., Weiss-Penzias, P. S., and Peterson, C.: Investigating sources of gaseous oxidized mercury in dry deposition at three sites across Florida, USA, Atmos. Chem. Phys., 12, 92019219, doi:10.5194/acp-12-9201-2012, 2012.

Shanley, J., Mast, M., Campbell, D., Aiken, G., Krabbenhoft, D., Hunt, R., Walker, J., Schuster, P., Chalmers, A., Aulenbach, B., Peters, N., Marvin-DiPasquale, M., Clow, D., and Shafer, M.: Comparison of total mercury and methylmercury cycling at five sites using the small watershed approach, Environ. Pollut., 154, 143-154, 2008.

Shanley, J., Engle, M. S., Krabbenhoft, D., Brunette, R., Olson, M., and Conroy, M.: High Mercury Wet Deposition at a "Clean Air" Site in Puerto Rico, Environ. Sci. Technol., 49, 12474-12482, 2015.

Sillman, S., Marsik, F., Dvonch, J. T., and Keeler, G. J.: Assessing atmospheric deposition of mercury in Florida, USA: Local versus global sources and models versus measurements, E3S Web of Conferences 2013, 1, 07008, 2013.

Slemr, F., Weigelt, A., Ebinghaus, R., Brenninkmeijer, C., Baker, A., Schuck, T., Rauthe-Schoch, A., Riede, H., Leedham, E., Hermann, M., van Velthoven, P., Oram, D., O'Sullivan, D., Dyroff, C., Zahn, A., and Ziereis, H.: Mercury Plumes in the Global Upper Troposphere Observed during Flights with the CARIBIC Observatory from May 2005 until June 2013, Atmosphere-Basel, 5, 342-369, doi:10.3390/Atmos5020342, 2014.

Sorensen, J. A., Glass, G. E., and Schmidt, K.: Regional patternsof wet mercury deposition, Environ. Sci. Technol., 12, 2025-2032, 1994.

Sprovieri, F., Pirrone, N., Gårdfeldt, K., and Sommar, J.: Mercury speciation in the marine boundary layer along a $6000 \mathrm{~km}$ cruise path around the Mediterranean Sea, Atmos. Environ., 37, 63-71, 2003.

Sprovieri, F., Hedgecock, I. M., and Pirrone, N.: An investigation of the origins of reactive gaseous mercury in the Mediterranean marine boundary layer, Atmos. Chem. Phys., 10, 3985-3997, doi:10.5194/acp-10-3985-2010, 2010a.

Sprovieri, F., Pirrone, N., Ebinghaus, R., and Kock, H.: A review of worldwide atmospheric mercury measurements, Atmos. Chem. Phys., 10, 8245-8265, doi:10.5194/acp-10-8245-2010, $2010 \mathrm{~b}$.

Sprovieri, F., Pirrone, N., Bencardino, M., D’Amore, F., Carbone, F., Cinnirella, S., Mannarino, V., Landis, M., Ebinghaus, R., Weigelt, A., Brunke, E.-G., Labuschagne, C., Martin, L., Munthe, J., Wängberg, I., Artaxo, P., Morais, F., Barbosa, H. D. M. J., Brito, J., Cairns, W., Barbante, C., Diéguez, M. D. C., Garcia, P. E., Dommergue, A., Angot, H., Magand, O., Skov, H., Horvat, M., Kotnik, J., Read, K. A., Neves, L. M., Gawlik, B. M., Sena, F., Mashyanov, N., Obolkin, V., Wip, D., Feng, X. B., Zhang, H., Fu, X., Ramachandran, R., Cossa, D., Knoery, J., Marusczak, N., Nerentorp, M., and Norstrom, C.: Atmospheric mercury concentrations observed at ground-based monitoring sites globally distributed in the framework of the GMOS network, Atmos. Chem. Phys., 16, 11915-11935, doi:10.5194/acp16-11915-2016, 2016. 
Steffen, A., Scherz, T., Olson, M., Gay, D., and Blanchard, P.: A comparison of data quality control protocols for atmospheric mercury speciation measurements, J. Environ. Monit., 14, 752$765,2012$.

Streets, D. G., Hao, J., Wu, Y., Jiang, J., Chan, M., Tian, H., and Feng, X.: Anthropogenic mercury emissions in China, Atmos. Environ., 39, 7789-7806, 2005.

Strode, S. A., Jaeglé, L., Selin, N. E., Jacob, D. J., Park, R. J., Yantosca, R. M., Mason, R. P., and Slemr, F.: Air-sea exchange in the global mercury cycle, Global Biogeochem. Cy., 21, GB1017, doi:10.1029/2006GB002766, 2007.

Strode, S. A., Jaeglé, L., Jaffe, D. A., Swartzendruber, P. C., Selin, N. E., Holmes, C., and Yantosca, R. M.: TransPacific transport of mercury, J. Geophys. Res., 113, D15305, doi:10.1029/2007JD009428, 2008.

Swartzendruber, P. C., Jaffe, D. A., Prestbo, E. M., Weiss-Penzias, P., Selin, N. E., Park, R., Jacob, D. J., Strode, S., and Jaeglé, L.: Observations of reactive gaseous mercury in the free troposphere at the Mount Bachelor Observatory, J. Geophys. Res.-Atmos., 111, D24301, doi:10.1029/2006JD007415, 2006.

UNI: EN 15853 - Ambient air quality - Standard method for the determination of mercury deposition, Tech. rep., UNI, Brussels, 2010.

Vanarsdale, A., Weiss, J., Keeler, G., Miller, E., Boulet, G., Brulotte, R., and Poissant, L.: Patterns of mercury deposition and concentration in northeastern North America, Ecotoxicology, 14, 37-52, doi:10.1007/s10646-004-6258-x, 2005.

Veiga, M., Maxson, P., and Hylander, L.: Origin of Mercury in Artisanal Gold Mining, J. Clean. Product., 14, 436-447, 2006.

Wan, Q., Feng, X. B., Lu, J. L., Zheng, W., Song, X. J., Han, S. J., and $\mathrm{Xu}, \mathrm{H}$.: Atmospheric mercury in Changbai mountain area, northeastern China I: The seasonal distribution pattern of total gaseous mercury and its potential sources, Environ. Res., 109, 201-206, 2009.
Wang, Y. M., Wang, D. Y., Meng, B., Peng, Y. L., Zhao, L., and Zhu, J. S.: Spatial and temporal distributions of total and methyl mercury in precipitation in core urban areas, Chongqing, China, Atmos. Chem. Phys., 12, 9417-9426, doi:10.5194/acp-12-94172012, 2012.

Wängberg, I., Munthe, J., Berg, T., Ebinghaus, R., Kock, H., Temme, C., Bieber, E., Spain, T., and Stolk, A.: Trends in air concentration and deposition of mercury in the coastal environment of the North Sea Area, Atmos. Environ., 41, 2612-2619, 2007.

Weiss-Penzias, P., Gustin, M., and Lyman, S.: Observations of speciated atmospheric mercury at three sites in Nevada: Evidence for a free tropospheric source of reactive gaseous mercury, J. Geophys. Res., 114, 2612-2619, 2009.

Wu, Y., Wang, S., Streets, D. G., Hao, J., Chan, M., and Jiang, J.: Trends in Anthropogenic Mercury Emissions in China from 1995 to 2003, Environ. Sci. Technol., 40, 5312-5318, 2006.

Xiao, Z., Sommar, J., Lindqvist, O., and Tan, H., and He, J.: tmospheric mercury deposition on Fanjing Mountain Nature Reserve, Guizhou, China, Chemosphere, 36, 2191-2200, 1998.

Zhang, L. and Wright, L.: A review of current knowledge concerning dry deposition of atmospheric mercury, Atmos. Environ., 43, 5853-5864, doi:10.1016/j.atmosenv.2009.08.019, 2009.

Zhang, L., Blanchard, P., Gay, D., Prestbo, E., Risch, M., Johnson, D., Narayan, J., Zsolway, R., Holsen, T., Miller, E., Castro, M., Graydon, J., Louis, V., and Dalziel, J.: Estimation of speciated and total mercury dry deposition at monitoring locations in eastern and central North America, Atmos. Chem. Phys., 12, 43274340, doi:10.5194/acp-12-4327-2012, 2012. 